\title{
Is corporate hedging always beneficial? A theoretical and empirical analysis
}

\author{
Hany Ahmed \\ Coventry University, UK \\ ad1856@ coventry.ac.uk \\ Richard Fairchild \\ University of Bath, UK \\ R.Fairchild@bath.ac.uk \\ Yilmaz Guney \\ University of Hull, UK \\ y.guney@hull.ac.uk
}

\section{Citation of this paper:}

Ahmed, H., Fairchild, R. and Guney, Y. (2020). Is corporate hedging always beneficial? A theoretical and empirical analysis European Journal of Finance, forthcoming.

\section{Acknowledgements:}

We would like to thank Tom Aabo, Lakshman Alles, Alberto Burchi, Xi Fu, John Goodell, Jayant Kale, Christodoulos Louca, Mark Shackleton and John Wingender for their constructive comments on the earlier versions of the paper. We are indebted to Khalid Ali, Zehan Hou, Chamaiporn Kumpamool, Yuhao Li and Ingga Wulandhari for their excellent research assistance for the data collection. 


\title{
Is corporate hedging always beneficial? A theoretical and empirical analysis
}

\begin{abstract}
This paper investigates, theoretically and empirically, the impact of corporate hedging activities on firm value/performance. In a perfect market, with self-less management, aiming to maximise shareholder wealth, it may be expected that hedging would improve firm performance and add value. Our major contribution in this paper is that we first demonstrate theoretically the conditions under which hedging can increase or decrease firm value. Our theoretic model demonstrates that the ambiguous relationship between hedging and firm value may be due to a subtle combination of economic (managerial self-interest, agency problems/moral hazard, managerial ability, managerial risk aversion) and behavioural factors (overconfidence). Our empirical analysis confirms the ambiguous effect of hedging on firm performance. Empirically, we focus on the use of derivatives in the corporate hedging of three types of financial risk (foreign currency, interest rate and commodity price risks), and examine the effect on value and performance of listed UK corporations during 2005-2017. We demonstrate that the positive or negative effects of the hedging strategies varies significantly across both the financial risk that is hedged and the type of derivatives contracts used in the hedging as well as the time period in consideration.
\end{abstract}

Keywords: Financial derivatives, Hedging, Performance, Value, UK firms, Risk management. JEL Classification: G30, G32. 


\section{Introduction}

In the face of extreme operational and financial risk, the decision whether to hedge risk becomes an important one for corporate managers. Should a firm expend resources in engaging in riskmanagement, and if so, which risks should be hedged, and how?

Since Modigliani and Miller's (MM, 1958) famous capital structure irrelevance theorem, a major area of research has been whether risk management is actually worthwhile. MM showed that, in a perfect market, risk-management is at best neutral (cannot add value), and, at worst, valuedestroying. In the intervening years, researchers have demonstrated, theoretically and empirically, that risk-management can add value due to market imperfections, i.e., risk-management becomes a worthwhile corporate activity.

However, does corporate risk-management always add value? In a perfect world, with self-less corporate management aligned with shareholders' interests, aiming to maximise shareholder-wealth, we would expect firms to only manage risk if it was expected to add value, and increase shareholder wealth. In this paper, we provide a major contribution to the risk-management research by considering, both theoretically and empirically, whether, in addition to being value-adding, firms could conduct risk-management activities which could actually end up being value-destroying. We first develop and analyse a theoretic model of corporate hedging. Our model demonstrates that the effect of corporate hedging on firm value is ambiguous (may be value-adding or value-destroying), due to a combination of economic (managerial self-interest, agency problems/moral hazard, managerial ability, managerial risk aversion) and behavioural factors (managerial overconfidence). We then test this ambiguity empirically. We focus on the use of derivatives in the corporate hedging of three types of financial risk (foreign currency, interest rate and commodity price risks), and examine the effect on value and performance of listed UK corporations during 2005-2017.

Another contribution of our analysis is that we introduce a new innovative concept into riskmanagement research: we term our new concept, the "Hedging-Speculation-Valuation Puzzle": we explain this concept as below:

\subsection{Hedging-Speculation-Valuation Puzzle}

In the MM world, corporate risk management policies and hedging have been a puzzle. MM (1958) suggested that, in a world of perfect frictionless capital markets, risk management and hedging are, at best, irrelevant activities for the firm (not able to add value), and, at worst, value-destroying (as they may be costly). One can contend that risk management and hedging are best left to external 
shareholders, who can diversify their own share portfolios, and reduce the risk that they face, using the capital markets. Of course, in the real-world, imperfections, such as agency problems, asymmetric information, capital market frictions, and corporate financial distress costs, provide a role for corporate risk management. We suggest that this solves one puzzle ("Why do firms manage risk?"), only to replace it with a new, deeper, puzzle, that we term, the "Hedging-SpeculationValuation Puzzle". This puzzle arises from the research in two areas: a) The firm's motives to manage risk (that is, the determinants of corporate risk management), and b) the effect of hedging on firm performance and value.

Smith and Stultz (1985) develop the seminal theoretical research on the determinants of corporate risk management. They analyse the optimal, value-maximising risk management policy of the firm. They suggest that risk management is employed to increase/maximise firm value. Corporations may manage risks in many ways. More recently, scholars have focussed on risk-management by use of financial derivatives (futures, forwards, options and swaps). A recent body of research has analysed the relationship between firms' use of derivatives to manage risk, and firm performance and valuation. The research has revealed mixed results. Some scholars have found a positive relationship: that is, increased usage of derivatives results in improved firm performance and increased valuation. On the contrary, some others have found a negative relationship: increased usage of derivatives results in a decrease in performance, and a reduction in firm value.

Drawing this research together provides our puzzle. The research in optimal risk management policy (e.g., Smith and Stultz, 1985) suggests that there should be a positive relationship between the use of derivatives for risk management purposes and firm value, whereas the empirical results are mixed. A further interesting complication that we note is that derivatives are a 'double-edged sword': they may be used by firms to decrease risk (the hedging motive). However, they can be used to increase risk (the speculation motive). Thus, our "Hedging-Speculation-Valuation Puzzle" puts forth two interesting research questions: a) When do firms choose to use derivatives to hedge, and when do they use derivatives to speculate? and b) When would firms' derivative usage (hedging or speculating) lead to an increase or decrease in firm value?

In this paper, we develop a theoretical model that addresses the "Hedging-Speculation-Valuation Puzzle", and provide some answers to our research question. ${ }^{1}$ Theoretically, our model is important, as it attempts to get inside the 'black box' of corporate risk management policy, to analyse managerial motives and effects on firm value. This will help empirical researchers to begin to understand the mixed results obtained, and to 'dig deeper' into the black box to test for managerial motives and determinants of risk management policy. A practical consideration for empirical 
researchers that our analysis emphasises is that, when analysing the determinants and effects of derivative usage, one must understand that derivatives can be used to hedge or speculate: existing research is silent on this, merely analysing the extent and presence of derivative usage.

We consider a corporate manager who makes two decisions: what risk management strategy to adopt (hedging, speculating, or neutral), and how much effort to exert in creating firm value. The ingredients of our model are as follows. First, unlike in the MM world, the manager is not acting purely in the interests of the shareholders: he is not aiming to maximise shareholder wealth. He is self-interested, and agency problems exist in the form of managerial moral hazard (in the form of both effort-shirking, and strategy choice). The second ingredient of the model is that, in making his risk-management choice, implicitly, using derivatives (the use of derivatives is not explicitly modelled), we recognise that derivatives are a double-edged sword. The manager can choose to (use derivatives to) hedge (reduce risk) or speculate (increase risk). Thus, when empiricists analyse the link between the extent of corporate derivative usage (as a hedging strategy) and firm value, and reveal mixed results, our analysis emphasises that they cannot be sure whether these firms are using derivatives for hedging (to reduce risk) or speculation (to increase risk). In addition to the manager's effort level, a further factor that may create a divergence in the manager's and the shareholders' preferred strategy choice is that the manager faces personal financial distress costs that may drive greater caution than the investors would like.

A third major ingredient that we introduce is drawn from the research in behavioural corporate finance (BCF): we consider the effect of managerial overconfidence. In BCF research, managerial overconfidence has been seen to have both positive (higher effort levels, more innovative activity, more entrepreneurship, more commitment to projects) and negative effects (excessive debt levels in the capital structure, excessive risk-taking, leading to problems such as financial distress and bankruptcy; entrapment into value-destroying projects).

Interestingly, there has been some empirical work on the effects of managerial overconfidence on corporate risk management and performance. The results are mixed, providing a strong motivation for our model, as we analyse the impact of managerial overconfidence on his motives to hedge or speculate, his effort levels, and the resulting impact on firm value (examining conditions under which overconfidence is value-increasing or decreasing).

In our model, a self-interested, possibly overconfident manager makes two decisions: a) Strategy decision: Whether to use derivatives to hedge (reduce risk), speculate (increase risk), or not use derivatives at all (no risk management). Having made his strategy decision, he decides on his effort level: exerting effort chases (increases) the upside, and escapes from (reduces) the downside 
performance of the firm. Overconfidence affects both decisions. As he becomes more overconfident, he overestimates his ability, and underestimates his financial distress costs in the case of the downside. This may drive him to more speculation, and to higher effort.

\subsection{Motivation for our analysis/literature review}

Financial derivatives usage is considered to be an important part of the risk management strategy of firms, and the level of notional amounts outstanding for the over-the-counter (OTC) derivatives in 2019 was over USD640 trillion and $81.8 \%$ of these were for interest rate contracts (Bank for International Settlements, BIS). Yet, whether these strategies are in line with the corporate hedging theories is debatable (Bartram et al., 2009; Tufano, 1996). Higher exposures to specific types of financial risks, overcoming costly external financing, accounting exposure, information asymmetries and agency costs have all been argued to influence corporate hedging strategies in practice (Aretz and Bartram, 2010; Bartram et al., 2011). Many non-financial firms have adopted different types of derivatives in hedging financial risks for pure risk mitigation or value creation purposes (Smith and Stulz, 1985). Risk management theories (Froot et al., 1993; Leland, 1998; Smith and Stulz, 1985) advocate that due to capital market imperfections, the use of derivatives for hedging may affect firm value, for instance, by reducing the expected taxes and financial distress costs, mitigating underinvestment and increasing debt capacity to take advantage of debt taxshields. Allayannis and Weston (2001), Carter et al. (2006), and Pérez-González and Yun (2013) provide empirical support for the benefits of hedging. Breeden and Viswanathan (2016) propose a model in which managers are assumed to use hedging to communicate their skills and reputation, which implies that-ex-ante- not all hedging decisions are rational in the sense that they are not beneficial or effective ex-post.

Nelson et al. (2005) study the effect of hedging on the market value of equity for 1,308 U.S. firms during 1995-1999. Their results show that only $21.6 \%$ of the firms are engaged with hedging activities and the hedgers outperform the nonhedgers by $4.3 \%$ per annum, on average. For the oil and gas industry, Jin and Jorion (2006) investigate the effect of hedging on firm value and find no significant differences between the hedgers and nonhedgers. For the airline industry, Carter et al. (2006) show that firms can benefit from following appropriate hedging strategies and firms value is positively associated with the intensity of the hedging. For the oil refinery industry, MacKay and Moeller (2007) find that hedging improves value when firms hedge concave revenues but leave concave costs exposed. Therefore, the literature provides mixed evidence. 
There are still a number of unexplored research questions in the literature. One of them is: does it matter which derivatives firms use? This consideration is relevant because understanding the effects of the choice of instruments on value and performance can provide further evidence as to why firms hedge, and which hedging strategies work. In practice, the majority of non-financial firms routinely use the popular derivatives but not all of them are likely to add value or improve performance. Despite the popularity of some derivatives used for foreign currency and commodity price risk hedging (i.e., forwards), other types are being used for interest rate risk hedging (i.e., options and swaps). ${ }^{2}$ Thus, empirically, we examine how different types of derivatives for hedging foreign currency, interest rate and commodity price risks could impact differently performance and value.

The second empirical question is: does the effect of hedging vary across years? It is reasonable to expect that firms would act differently if 'high commodity prices, high interest rates and stable market' times become 'low commodity prices, low interest rates and volatile market' times. As a consequence, the necessity and the level of commitment to hedging activities, and the impact of hedging on value and performance of firms may evolve overtime. The third empirical question is: hedging which financial risk yields more favourable outcomes? The importance of this issue has been raised by Nelson et al. (2005) who find that, although overall hedging is associated with abnormal stock returns, it is actually foreign currency hedging that leads to this positive outcome, not the interest rate or commodity price hedging. To address these questions and hence to complement the literature, we use hand-collected data for 378 non-financial firms listed in the FTSE-All Share Index over the time period between 2005 and 2017.

An important issue raised by the extant studies relates to potential endogeneity problems or selfselection bias in regressions when predicting the influence of derivatives usage on performance or value. Hedging decisions are unlikely to be exogenous to firms, and for hedgers and nonhedgers the value or importance of hedging can be very different. Chen (2011) addresses the endogeneity problem by using the two-stage least squares (2SLS) method for the determinants of derivatives use and performance. Chen and King (2014) use various methods to ensure that endogeneity or selfselection problems are mitigated. Furthermore, although prior studies examined whether hedging a specific risk or using a specific contract affects firm value (Carter et al., 2006; Bartram and Bodnar, 2007; Allayannis et al., 2012), comparing the effect of specific derivatives in hedging a specific financial risk in a comprehensive way has not been attempted. Bessembinder (1991) investigates forwards; Carter et al. (2006) study commodity price risk hedging; Bartram and Bodnar (2007), and Allayannis et al. (2012) examine foreign exchange risk hedging. 
Prior research (e.g., Allayannis and Weston, 2001; Bartram et al., 2011) examines the effect of active risk management policies with specific derivatives across countries or industries. For example, Bartram et al. (2011) show in their univariate analysis that examining various derivatives contracts can give rise to an interesting investigation of the effectiveness of derivatives. As multinational firms are regularly exposed to risks related to cash flows in foreign currency and investments in various countries, Chang and Wong (2003) provide strong evidence for the optimality of using options and futures in FX risk hedging. In fact, studies on risk hedging with derivatives such as a survey by Bodnar et al. (2013) provide mixed results for estimating the probability of IR risk hedging with forwards and options. Pérez-González and Yun (2013) find a positive relationship between weather derivatives and firm value for the energy firms. Similarly, Chernenko and Faulkender (2011) find that interest rate swaps are being used especially by highinvestment firms possibly due to costly external finance. This implies how hedging via different instruments can lead to different outcomes with respect to cost of borrowing, value or performance.

The existing literature reports a number of firm-specific factors that affect hedging decisions and finds that geographic diversification policy affects firms' commitment to hedging and the hedging affects firm value (see e.g., Bartram et al., 2011). Allayannis et al. (2012) suggest that the use of derivatives for foreign currency risk hedging is positively associated with a value premium if firms have a strong internal (firm-level) or external (country-level) governance. Unlike Pérez-González and Yun (2013), Tufano (1996) finds weak evidence that risk management maximizes shareholders' value and shows that firms whose managers hold more stocks are more prone to hedge the gold price risk. Borokhovich et al. (2004) find a positive and significant relationship between the relative influence of outside directors and interest rate risk hedging, using a sample of 370 firms listed in the S\&P 500 index. Dhanani et al.'s (2007) survey based on 564 UK non-financial listed firms examines whether tax, regulatory arbitrage, managing the variability of reported earnings, managerial incentives, economies of scale and lowering the likelihood of financial distress determine interest rate risk hedging. While some responses support the above theories, others do not. Conventional wisdom says that mandatory hedging, for instance through debt covenants, does not help firms maximize value. Nevertheless, Marami and Dubois (2013) show that affirmative covenants, such as those that require firms to comply with accounting rules, pay taxes and buy insurance, favours value creation whereas voluntary IR hedging does not affect firm value. There are also studies providing mixed results for the effect of hedging on value and performance. For instance, Dhanani et al. (2007) argue that the effect of hedging on firm value varies across countries and is affected by the tax regime and regulatory rules, and Fauver and Naranjo (2010) argue that the 
link between hedging and firm value is negative for firms with weak corporate governance. Additionally, Faulkender (2005) reports a strong association between the slope of the yield curve and interest rate risk hedging; Géczy et al. (2007) argue that derivatives can be used to inflate performance-based compensation, given that it is difficult to distinguish between the use of derivatives for hedging and speculative purposes. Bartram et al. (2011), relying on a sample which includes 6,888 non-financial firms from 47 countries, show that the use of derivatives reduces firms' total risk, is positively associated with firm value and more prevalent in firms with higher exposures to interest rate, exchange rate and commodity prices risks. Other studies examine whether business geographic diversification affects firms' commitment to hedging and if this is related to firm value (see e.g., Allayannis and Weston, 2001). Bonaimé et al. (2014), on the other hand, show that the need for hedging can be mitigated by more active corporate payout policy.

In perfect markets, one would expect the gains from speculative hedging to be zero or negative given the transaction costs. Adam and Fernando (2006) suggest that the gains from speculative hedging appear small. Despite recent developments in the literature, we still have little theoretical explanatory power to identify which firms ought to use derivatives, noting that sub-optimal, inappropriate or unnecessary usage of derivatives may lead to unwanted effect on firm value or performance. It is possible that the motivation for risk management may be due to factors not yet considered in risk management theories, such as earnings smoothing, industry competition, a manager's self-interest, speculative purpose or signalling, which are challenging to study empirically. During the financial crisis period, firms may have used derivatives to signal investors that their business was protected against unfavourable market moves. Furthermore, most empirical studies fail to account for the endogeneity of variables, which may describe different dimensions of the risk management strategy and financial policies, as stressed by Aretz and Bartram (2010).

Our paper's empirical approach is distinct from the previous literature in the following aspects: first, it studies the use of four derivative contracts: futures, forwards, options and swaps on the hedging of three types of risks: foreign currency (FX), commodity price $(\mathrm{CM})$ and interest rates (IR). Previous studies rely on samples that focus either on a specific risk, without specifying which derivatives are used for hedging, or on specific derivatives without specifying which risks the derivatives used is hedging, or on the study of whether the use of derivatives for hedging is associated with firm value and performance. There are studies (e.g., Bodnar et al., 2013) which provide statistics on both the usage of various derivatives for hedging different risks but these studies have a qualitative nature where respondents are asked to rank the derivatives they use without linking each of the derivatives to a specific risk management. We consider both the risks 
that are hedged and the derivatives used in the hedging, and to the best of our knowledge there is no paper that analyses the impact of hedging with respect to various derivative contracts.

Second, our analysis examines univariately and multivariately the use and effectiveness of hedging activities across different years and time periods ((pre-crisis (before 2007) and post-crisis periods (after 2009), during crisis (2007-2009) and non-crisis years that before 2007 and after 2009)). Bartram et al. (2011) focused on the economic downturn in 2001-2002 in the USA and Panaretou (2014) focused on the latest crisis period covering years 2007 to 2010 in the UK. However, we use more robust and appropriate techniques to address the issue whether hedging would have different effects on firm value and performance at different times. Such analyses would be appropriate to figure out whether there are specific years or time periods when hedging provides particular benefits and when it actually impedes performance or value.

Third, our econometric techniques provide robust analyses by using propensity score matching (PSM) with new features and treatment effects (TE) methods to consider the selection bias problem and address the endogeneity problem. Furthermore, we use the recently developed technique called difference-in-differences approach combined with PSM (labelled as DDM) to compare the results across different time periods (i.e., pre-crisis, post-crisis and during crisis years). To our best knowledge, no paper has analyzed the impact of hedging on firm outcomes across different times using this method. The importance and relevance of such robust methods are shown in this study as some of our regression results are sensitive to whether we control for the econometric issues of endogeneity or sample-selection bias problems. Overall, we contribute to the literature by confirming that the real effect of hedging on firm value and performance can be better understood when the analysis is conducted separately for each derivative contract and we also show that the impact of hedging on value and performance is time-variant.

Our key empirical findings are as follows: first, overall foreign currency hedging increases both performance and value whereas overall commodity price and interest rate hedging impedes both firm value and financial performance. Moreover, we observe that the association of performance and value with hedging varies across different derivatives even for the same risk type: forwards and swaps for hedging FX have positive effects on return on assets (ROA) but options and swaps in hedging IR risk reduce performance; using forwards or swaps (options) for the FX risk increases (decreases) value; when swaps or options (forwards) are used for the IR risk firm value reduces (increases); and CM hedging improves value only when options are used. Chernenko and Faulkender (2011) highlight the fact that some firms use IR hedging via swaps for speculative purposes. Similarly, Faulkender (2005) implies that managers can get myopic (as an irrational 
attitude) and use IR hedging contracts to time the market. These issues may partly explain as to why IR hedging yields negative outcomes. Furthermore, if managers opt for speculative hedging, this is unlikely to generate value for shareholders (Adam et al., 2017; Adam and Fernando, 2006).

Second, the PSM technique reveals that the matched firms in the FX hedgers sample have higher value compared to the nonhedgers with no significant effects on ROA; these results are valid for any contract. The effects of IR hedging on both outcomes are negative when options or swaps are used. The impact of hedging CM risk on ROA (value) is negative (positive); ROA results hold for all contracts but mainly futures support the results for value.

Third, the PSM method across four time periods show that hedging can influence value and performance differently depending on the market conditions and derivatives types. For instance, we obtain that during the crisis times market value is improved only for foreign currency hedging. The DDM results suggest that the incremental positive effect on firm value is higher during post-crisis times relative to the pre-crisis times and that the negative effect of IR hedging on firm value is more salient when forwards are used during crisis years relative to non-crisis years. This set of results implies that it matters when the hedging is conducted.

The risk hedging strategy with the respective hedging instruments is clearly an important question for any firm that hedges, and analysing the outcomes of the use of various risk hedging instruments can provide indirect evidence as to: i) why firms hedge in the market imperfections, and ii) why firms should evaluate the type of hedging instruments and consider carefully the hedging instruments choice at an optimal hedging level. To shed light on this area, this paper comprehensively investigates how different types of contracts with respect to different types of risks in time-varying perspective could lead to adding or destroying firm value and performance.

The rest of the paper is structured as follows. In section 2, we develop and analyse our theoretic model of corporate hedging/speculation, and the (positive and negative) effects on firm value. Section 3 describes our sample, the data collection procedures and presents the descriptive statistics. Section 4 reports the empirical results. Section 5 concludes.

\section{A Game-Theoretic Approach to Hedging Decisions}

In our subsequent empirical analysis, we analyse the effect of corporate hedging decisions on firm performance. In a perfect world, it may be assumed that managers, acting in shareholders' interests, would be motivated to hedge 'perfectly' in order to increase or maximise shareholder value. However, our empirical analysis reveals mixed results, in that the managerial use of derivatives (our 
empirical measure of risk management) results in value increase and performance increase in some cases: however, in other circumstances, such risk management activity actually results in valuereduction, and impairs corporate performance. The question then becomes: why do we get these mixed results? Why do managers sometimes 'get it wrong' in terms of value-destroying risk management?

In this section, we develop a game-theoretic analysis that provides potential answers to this question, by considering corporate managers' risk management motives, and the effect on firm value. Our model provides economic (agency) and behavioural (psychological/emotional) reasons why managerial risk management strategies are not necessarily value-enhancing, and may actually destroy value: in other words, managers' risk management policies may be in conflict with their shareholders' objectives due to managers' self-interested agency reasons, and/or due to managerial psychology.

Before developing our model, we note a complication. In our empirical analysis, we consider two groups of firms: hedgers (who report that they use derivatives), and non-hedgers, who do not. Thus, we assume that the firms that use derivatives are doing so for hedging purposes. However, Géczy et al. (2007), for example, note that a firm's use of derivatives can be a 'double-edged' sword. The derivatives may be used to reduce risk (which is the hedging motive): however, they can also be used to increase risk (the speculation motive). From our empirical analysis, it is not clear whether firms are hedging or speculating: it is just that those that use derivatives sometimes increase value and performance, and other times, reduce it.

Thus, our theoretical analysis in this section considers managerial motives for both hedging and speculating with derivatives, and in both cases, when this may be value-adding or value-destroying. We consider a corporate finance manager, running a project for his company, who has two decisions to make around the project; $i$ ) a hedging decision (that is, no hedging $N H$, hedging $H$, and speculation $S$ ). and ii) the effort level " $e$ " to exert into the project: effort is costly; the cost of effort is $\beta e^{2}$.

The project's outcome has a binomial distribution: that is, it succeeds with probability $P \in[0,1]$, and fails with probability $1-P$. The manager's hedging choice affects the success and failure outcomes. The manager's effort level further increases the success outcome. We model these two effects as follows:

The failure outcome from each strategy is: $V_{0}-\Delta_{i}(1+F)$. The success outcome from each strategy is $V_{0}+\Delta_{i}(1+\gamma e)$, where $i \in\{L, M, H\}$ (that is, low, medium or high) for the hedging, no hedging, 
and speculative strategies, respectively. Note that $\Delta_{H}>\Delta_{M}>\Delta_{L}$; this implies that, considering the case where $e=0, F=0$, in comparison to the 'no-hedging' case, hedging reduces the upside and downside variance (risk) in income around $V_{0}$, whilst speculating increases the upside and downside risk around $V_{0}$.

Furthermore, we consider the possibility that the downside leads to some financial distress for the firm, represented by $F \geq 0$. On the upside, the manager's effort level increases the upside income: $\gamma$ represents the manager's ability. In addition to the financial distress faced by the firm, we also consider the possibility that the manager faces some additional 'personal/perceived' financial distress costs $F_{M} \Delta_{i}$ in the downside case: this may reflect him having all of his human capital tied up in the business, the economic costs of his lost reputation from running a failing business (thus losing future employment opportunities) and such behavioural costs as anxiety, regret and anger. Hence, in making his hedging choice (hedging, no hedging, or speculation), the manager considers both the probability of the upside and downside ( $P$ and $1-P$ ), the amount of income he can add in the upside due to his effort level combined with his ability, and the firm-level and personal financial distress costs in the case of the downside. We will observe that he will not necessarily want to hedge to reduce risk: if he perceives (see our discussion below on overconfidence: hence, 'perceives') that the success probability, and/or his ability is sufficiently high, and the downside financial distress risk is sufficiently low, he may choose to speculate.

We adopt a behavioural corporate finance (BCF) approach by considering the effect of managerial overconfidence on the manager's decision-making. In our model, the manager may be overconfident about his ability, about the success probability, and/or about the downside financial distress (i.e., he underestimates it): thus, we consider $\hat{\gamma} \geq \gamma ; \hat{P} \geq P ; \hat{F} \leq F$. The sign '^' represents the overconfident manager's perception of these variables; without this hat sign we refer to the true levels of these variables. In the benchmark case, a fully-rational (i.e., homo economicus) manager is fully aware of the true parameter values: $\hat{\gamma}=\gamma ; \hat{P}=P ; \hat{F}=F$. Increasing each of the 'hatted' variables represents increasing overconfidence in respect to that variable. Hence, our model incorporates both moral hazard (in the form of managerial effort-shirking) and BCF in the form of managerial overconfidence.

Given the success and failure outcomes given above, and the success and failure probabilities, the expected value of the firm under strategy $s$ can be written as: 
$V_{s}=P\left(V_{0}+\Delta_{i}(1+\gamma e)\right)+(1-P)\left(V_{0}-\Delta_{i}(1+F)\right)$.

which can be re-written as:

$V_{s}=V_{0}+P \Delta_{i}(2+\gamma e+F)-\Delta_{i}(1+F)$.

where strategy $s \in\{H ; N H ; S\}$ brings $\Delta_{i} \in\left\{\Delta_{L} ; \Delta_{M} ; \Delta_{H}\right\}$, respectively.

It is interesting to note that, in Eq. (1a), when $P=0, V_{S}=V_{0}-\Delta_{i}(1+F)$; since there is no chance of success, the firm faces the downside for sure, including the financial distress costs $F$. When $P=1, V_{S}=V_{0}+\Delta_{i}(1+\gamma e)$, the firm achieves the upside for sure, which is enhanced by managerial effort. When $P=\frac{1}{2}, V_{S}=V_{0}+\Delta_{i}\left(\frac{\gamma e-F}{2}\right)$, the upside enhancement due to managerial effort offsets the downside financial distress costs. In the case where $\gamma e=F$, they exactly balance, and the expected value when $P=\frac{1}{2}$ is $V_{S}=V_{0}$; that is, the distribution is symmetric around $V_{0}$.

We assume that the manager holds an 'equity stake' $\alpha \in[0,1]$ in the project. The (overconfident) manager's perceived payoff represents the perceived value of his equity stake minus his effort costs:

$$
\hat{\Pi}=\alpha \hat{V}-\beta e^{2}-(1-\hat{P}) \Delta_{i} F_{M}
$$

where the manager's perception of firm value comes from equation 1a, incorporating the manager's three perceived parameter values:

$$
\hat{V}_{s}=V_{0}+\hat{P} \Delta_{i}(2+\hat{\gamma} e+\hat{F})-\Delta_{i}(1+\hat{F}) \text {. }
$$

As is standard in game-theoretic approaches, we solve by backward induction. That is, we first take as given the manager's choice of strategy, and solve for his optimal effort level, and then we move back to solve for his optimal hedging strategy.

Given the manager's choice of strategy $s \in\{H ; N H ; S\}$, we substitute (3) into (2), and then we solve $\frac{\partial \hat{\prod}}{\partial e}=0$ in order to obtain the manager's optimal effort level $e^{*}$. We obtain

$$
e^{*}=\frac{\alpha \hat{P} \hat{\gamma} \Delta_{i}}{2 \beta} .
$$


Hence, the manager's optimal effort level is increasing in his 'equity stake' $\alpha$, and his perceptions of the success probability and his ability: increasing overconfidence in either increases his effort level to 'chase the upside'. Furthermore, his optimal effort level is increasing in the upside/downside variance $\Delta_{i}$. This reveals that he will work hardest in the case of speculation to chase a high upside; he will work at the medium level in the case of no-hedging, and he will work at the lowest level in the case of hedging, since there is a low upside to be chased.

We substitute (4) into (3) and then into (2) to obtain the manager's perceived indirect payoff (that is, his perceived payoff incorporating his optimal effort level). We also substitute (4) into (1a) to obtain the true value of the project. We then obtain:

$$
V_{s}=V_{0}+P\left[\Delta_{i}\left(2+F+\frac{\alpha \hat{P} \hat{\gamma} \gamma \Delta_{i}}{2 \beta}\right)\right]-\Delta_{i}(1+F) .
$$

It is worth considering the manager's perception of the project value as follows:

$$
\hat{V}_{s}=V_{0}+\hat{P}\left[\Delta_{i}\left(2+\hat{F}+\frac{\alpha \hat{P} \hat{\gamma}^{2} \Delta_{i}}{2 \beta}\right)\right]-\Delta_{i}(1+\hat{F})
$$

The manager's perceived payoff is:

$$
\left.\left.\hat{\Pi}=\alpha V_{0}+\frac{\alpha^{2} \hat{P}^{2} \hat{\gamma}^{2} \Delta_{i}}{4 \beta}\right)\right]-\alpha\left[\hat{P} \Delta_{i}(2+\hat{F})-\Delta_{i}(1+\hat{F})\right]--(1-\hat{P}) \Delta_{i} F_{M} .
$$

Finally, we move back to consider the manager's optimal hedging strategy. He chooses his optimal strategy to maximise his perceived payoff (6). Thus, he recognises that his choice of strategy affects the level of the upside and downside, and that he will subsequently exert effort to chase the upside. His choice will further be affected by his (overconfident) perception of the upside probability, his ability, and the downside firm-level and personal/perceived financial distress costs (overconfidence implies that he overestimates the first two factors, and underestimates the final two factors: however, the final factor, personal/perceived financial distress costs is increasing in his personal economic (e.g., reputation) and behavioural/psychological/emotional costs (e.g., anxiety, regret, anger). In order to clarify our analysis, we consider numerical examples shown as follows.

$V_{0}=1,000,000 ; \quad P=0.5 ; \quad F=0.5 ; \Delta_{L}=5,000 ; \Delta_{M}=10,000 ; \Delta_{H}=20,000 . \alpha=0.2$.

In addition to these fixed parameters, we also consider the effect of two levels of true ability; $\gamma=10$; and $\gamma=0$. We anchor the overconfidence level to the true ability level such that in the first case, we consider overconfidence in the interval $\hat{\gamma} \in[10,19]$, while, in the second case, we consider 
overconfidence in the interval $\hat{\gamma} \in[0,9]$. Furthermore, in both cases, we consider various levels of managerial personal/perceived financial distress costs.

Case 1: High true ability: $\gamma=10$.

We consider the effects of managerial overconfidence on the manager's hedging strategies and firm value as follows. We first consider a true managerial ability at high level. In our numerical example, we assume that the manager is only overconfident about his ability: hence, he understands the true level of success probability and financial distress costs: thus;

$$
P=\widehat{P}=0.5 \text { and } F=\hat{F}=0.5 \text {. }
$$

We consider his perceived ability in the interval $\hat{\gamma} \in[10,19]$. With high true ability, he is well-

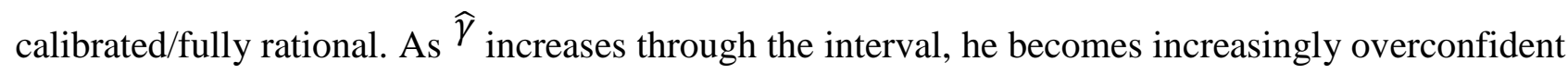
about his ability. Furthermore, we consider the effect of increases in the manager's personal financial distress costs. The high true-ability case, with overconfidence and increasing managerial personal financial distress costs, is represented in figures 1-5.

\section{[INSERT FIGURES 1-5 HERE]}

In figure 1, the manager's effort level is increasing in overconfidence for each of the hedgingstrategies. This is the benefit of overconfidence: it reduces the moral hazard (effort-shirking) problem, as the manager works harder. Also, at any level of overconfidence, the manager works hardest under the speculative strategy, works at the medium level under the 'no hedging' strategy, and works at the lowest level under the hedging strategy. This is due to 'chasing the potential upside' rewards, which are greatest/medium/least under the speculative/no risk management/hedging strategies, respectively.

Figure 2 mirrors figure 1: the true project value is increasing in the level of managerial overconfidence, as he increases his effort level. Furthermore, given our parameter values, for any level of overconfidence, firm value is highest/medium/lowest for the speculative strategy/no riskmanagement/risk management strategies, respectively. Figure 3 mirrors figures 1 and 2: the (high true ability) overconfident manager perceives that his payoff is highest under the speculative strategy: noting that the manager faces zero financial distress costs in the downside, he thus chooses the speculative strategy for any level of overconfidence, and this maximises project value as he has 
high true ability. Further, the manager's perceived payoff is a) increasing in overconfidence for each strategy, and b) for a given level of overconfidence, his payoff is highest/medium/lowest for the speculative strategy/no risk-management/risk management strategies, respectively.

Figure 4 demonstrates that, with medium personal financial distress costs (in the case of downside) for the manager, he now selects the risk-management (hedging) strategy for low levels of overconfidence (which minimises firm value), but switches to the project maximising speculative strategy as overconfidence increases beyond a critical level. Compared to figure 3 , all of the perceived payoff loci shift downwards, and cross each other. In figure 3, the manager unambiguously chose the (value-maximising) speculative strategy for any level of overconfidence. Now, in figure 4, with medium financial distress costs, he chooses the risk-management strategy for low overconfidence (in the interval $\hat{\gamma} \in[10,13]$ ). Then, he switches to the speculative strategy for high overconfidence $\hat{\gamma}>13$. In figure 2 , firm value runs along the lowest loci (RM: hence firm value is minimised), in the interval $\hat{\gamma} \in[10,13]$, then jumps to the highest value-maximising loci at $\hat{\gamma}=13$.

Figure 5 demonstrates that, as personal financial distress costs increase, there is an increase in the critical level of overconfidence at which the manager switches from the value-minimising to valuemaximising speculative strategy. Thus, the manager hedges for a larger interval of overconfidence, switching to speculation at a higher level of overconfidence. Compared with figure 4 , in figure 5 , high financial distress costs cause the perceived payoff loci for non-risk-management and speculative strategies to shift downwards below the risk management strategy for any level of overconfidence. Now, personal financial distress costs dominate overconfidence, and the manager chooses risk management for any level of overconfidence. Note that in figure 2, this minimises firm value (the lowest loci).

In summary, in our benchmark case of high true ability (i.e., $\gamma=10$ ), speculation maximises firm value, as the manager is sufficiently skilled to chase the upside. Overconfidence is unambiguously good for shareholders: higher overconfidence results in higher effort levels, and the manager chooses speculation for any level of overconfidence when his personal financial distress costs are zero. For medium levels of personal financial distress costs, a manager with a low level of overconfidence chooses the third-best (value-minimising) hedging/risk management strategy, while he switches to value-maximising speculation for high levels of overconfidence. As the personal 
financial distress costs increase, the switching threshold level of overconfidence 'shifts right': thus very high levels of personal financial distress costs dominate managerial overconfidence, and the manager chooses value-minimising hedging for any level of overconfidence.

Case 2: no true managerial ability: $\gamma=0$.

We now consider another extreme: the case where the manager has no true ability. The fixed parameters remain as before. We now consider overconfidence in the interval $\gamma \in[0,9]$. The zeroability case is represented in figures 6 to 11 .

\section{[INSERT FIGURES 6-11 HERE]}

As in figure 1, figure 6 depicts that effort level is increasing in overconfidence for each strategy, and for a given level of overconfidence, effort is highest/medium/lowest for the speculative strategy/no risk-management/risk management strategies, respectively, because the manager is motivated to chase the upside. Although the shape of this figure is the same as in figure 1, note the vertical axes in each figure: due to a lower range of ability-overconfidence, the optimal effort levels are lower in figure 6 compared to figure 1. Recall also that in the previous case high true ability resulted in the manager choosing value-maximising speculation.

Figures 7 and 8 introduce an interesting contrast in the current low ability case, compared with the previous high-ability case (comparing figure 7 with figure 2). In figure 8 , the manager unambiguously chooses the speculative strategy for any level of overconfidence (as he did in the high ability case: figure 3). In figure 8 , the manager's perceived payoff is a) increasing in overconfidence for each strategy, and b) for a given level of overconfidence, his payoff is highest/medium/lowest for the speculative strategy/no risk-management/risk management strategies, respectively. Note that the manager faces zero financial distress costs in the downside. Since he has low true ability, this minimises true value for any level of overconfidence. See figure 7 and also notice the contrast with the high ability case.

However, figure 7 confirms that, in the current case, due to zero true ability, the manager's chosen speculation strategy is now the third-best value-minimising strategy; and his effort level has no effect on the true value of the firm (hence, the horizontal loci). Now, in contrast to the previous case, hedging is value-maximising and overconfidence is value-destroying, as the overconfident 
manager chooses value-minimising speculation. Thus, in contrast to figure 2 (where firm value was maximised under speculation, due to high managerial ability), firm value is now maximised under risk management for any level of overconfidence (due to low managerial ability).

Now, we consider the effects of introducing and increasing managerial personal financial distress costs in figures 9 to 11 . As in the previous high-ability case, the manager chooses the riskmanagement (hedging) strategy for low levels of overconfidence, and switches to speculation for high levels of overconfidence. As the manager's personal financial distress costs increase, the critical level of overconfidence at which he switches increases. In contrast to the high ability case, hedging is value-maximising, and speculation is value-destroying. Thus, high overconfidence destroys value.

In figure 9, we introduce medium personal financial distress costs for the manager. Compared to figure 8 , all of the perceived payoff loci shift downwards, and cross each other. In figure 8 again, the manager unambiguously chose the (value-minimising) speculative strategy for any level of overconfidence. Now, in figure 9, with medium financial distress costs, he chooses the riskmanagement strategy for low overconfidence (in the interval $\hat{\gamma} \in[0,3]$ ). Then, he switches to the speculative strategy for high overconfidence $\hat{\gamma}>3$. Note that in figure 7 , firm value run along the highest loci (RM: hence firm value is maximised). When $\hat{\gamma}>3$, the overconfident manager switched to the speculative strategy, and firm value jumped down to the lowest locus in figure 7 . Note the contrast with the high ability case, where the speculative strategy maximised firm value. Now, in the low ability case, it minimises it.

In figure 10, as the personal financial distress costs of managers increase to high levels, the loci shift further downwards. Now, the overconfidence range in which the manager chooses the riskmanagement strategy increases from $\hat{\gamma} \in[0,3]$ to $\hat{\gamma} \in[0,6]$. Then, he switches to the speculative strategy for high overconfidence $\hat{\gamma}>6$. Note that in figure 7 , firm value run along the lowest loci (RM: hence firm value is minimised), in the interval $\hat{\gamma} \in[0,6]$, then jumped downwards to the lowest value-maximising loci at $\hat{\gamma}=6$. Finally, in the case of very high personal financial distress costs in figure 11, the speculative and no risk-management loci have shifted down so far, that the risk-management locus dominates for all levels of overconfidence. Thus, the manager chooses the value-maximising risk-management strategy for any level of overconfidence. 
In summary, the manager's choice of strategy (speculation or hedging) and the effect of firm value is crucially affected by a complex mix of true managerial ability, managerial overconfidence, firmlevel financial distress costs, and the manager's personal/perceived level of financial distress costs. We have demonstrated that speculation can be beneficial for shareholder wealth (when true ability to chase the upside is sufficiently high), whilst hedging is preferable when true ability is low. At the same time, the manager's choice of these strategies, and the effect on firm value, is affected by a trade-off between overconfidence in his ability (driving him towards speculation) and his concerns over downside financial distress, both at the firm- and personal level (driving him towards hedging). This is summarised in table A2 in the Appendix. The results in table A2 are consistent with the appendix graphs, as just described. Panel A in Table A2 considers the case when manager has very high true ability (such that speculation is always shareholder value-maximising: hedging is inefficient): this panel demonstrates his choice of strategy, and effect on firm value. Panel B in table A2 considers the case when manager has very low true ability (such that hedging is always shareholder value-maximising: speculation is inefficient): this panel demonstrates his choice of strategy, and effect on firm value. 'Hedging' is shown in bold: so that the reader can easily observe the creeping increase in hedging as managerial financial distress increases.

The model developed in this section- together with figures and tables- has demonstrated that the relationship between managerial economic incentives (for example, his equity stake in the project, economic upside-incentives, economic down-side financial distress, economic ability and effort costs), his behavioural factors (such as overconfidence and anxiety), the psychological and personal threat of financial distress, the manager's derivative strategy choice (hedging or speculating), and the effect on firm value (increasing or decreasing) is complex and ambiguous. High true ability implies that speculation may be first best (shareholder wealth maximising) as the manager 'chases the upside', while hedging is inefficient. Low true ability implies the reverse: hedging may be first best (as managers seek to reduce the downside threat), while speculation is inefficient. The manager's choice of strategy is crucially affected by the trade-off between overconfidence in his ability (driving the manager towards speculation) and overestimation (higher perception) of financial distress, driving him towards hedging.

In our subsequent empirical analysis, we will analyse the relationship between the use of derivatives and firm value. Our empirical analysis looks at whether firms use derivatives or not, but is unable to analyse whether they are used for hedging or speculation. Furthermore, we do not have any handle 
on the manager's motives (we do not have any information on overconfidence or financial distress costs). The contribution of our model is to demonstrate the complex relationships outlined above, and to show that, under certain conditions, the manager may be driven to use first-best derivative strategies (hedging or speculation): on other occasions, he may be driven to use second-best derivative strategies (again, hedging or speculation). This provides some explanation for why we find empirically that in some cases, the manager's derivative usage (either hedging or speculation) increases firm value, while in other cases, it reduces it. This latter, second best, case could be because he is overconfident, and is speculating when hedging would have been best for the shareholders, or it could be because he overestimates financial distress, and he hedges when speculation would have been best for shareholders.

\section{Data and descriptive statistics}

\subsection{Data sources and sample construction}

We examine the effect of derivatives use on value and performance of the non-financial firms listed in the FTSE-All Share Index during 2005 to 2017. This index is capitalization-weighted with a base level of 100 which started in April 1962. Currently it comprises around 640 constituents, from a group of more than 2,000 firms quoted in the London Stock Exchange, and it captures roughly 98\% of the UK's market capitalization. In the UK, after the implementation of Financial Reporting Standard (FRS) 13 ('derivatives and other financial instruments: disclosures') in 1999, the firms were required to report externally their hedging activities based on financial instruments. Prior to January 2005, they accounted for derivatives in accordance with UK generally accepted accounting principles (GAAP) on their income statements albeit non-detailed information. From April 2005, hedge accounting for the quoted firms has then been shaped by International Financial Reporting Standards (IFRS). The International Accounting Standards (IAS) 32 ('financial instruments disclosures and presentation') and IAS 39 ('financial instruments: recognition and measurement') increased both the transparency and the quality of risk management-related information provided in the annual reports. The new hedging accounting standards seek to inform investors of the results of the hedging activities by reporting information on the risks that are hedged and the effects of hedging over a given time period. Following the adoption of IAS 39 (that replaced FRS 13) in 2005, firms recognized the hedging instruments at fair value on their balance sheets as it became mandatory for them to disclose all documentations. 
Given the difficulty of data collection for nonfinancial firms in our sample and of determining the correct size, sign of derivatives positions, and hedging vs. trading generally (due to inconsistent information, financial disclosures, hedge accounting treatments, etc.), we only use binary indicators to quantify firms' derivatives policy throughout the paper.

We have collected the commentary on the firms' financial disclosure in relation to their objectives, policies and processes for managing their hedging decisions, financial risk management objectives, details of their financial instruments and hedging activities that related to hedging purposes. In addition, we have read and analysed, during the data collection process, the hedge accounting materials to review the respective hedging instrument usage. Furthermore, we have assessed any major impact on the firms' current accounting treatment with the respect to hedging activities if applicable.

It is noted in firms' financial disclosure that firms use derivative financial instruments to hedge their exposure to foreign exchange, interest rate and commodity risks arising from operating, financing and investing activities. For those that are held as "hedging instruments" are formally designated as hedges as defined in IAS 39. In our sample, firms' risk management practices do not hold or issue derivative financial instruments for speculation purposes, however, if derivatives do not qualify for hedge accounting, they are accounted for as "held for trading".

For a sample comprising 378 firms with 4,210 observations, this paper documents that nonfinancial firms in our sample use derivatives to hedge exposure to marks risks and not for speculations. There is no evidence of corporate speculation with derivatives for individual firms for different types of derivatives in different types of risks, except for some derivatives do not qualify for hedge accounting or are specifically not designated as a hedge where gains and losses on the hedging instrument and the hedged item naturally offset in the firm's income statement.

The data on derivatives usage were hand-collected from annual reports whereas the remaining data were collected from Thomson Reuters EIKON and Bloomberg. Annual reports were downloaded from firms' official websites. We followed the methods of Nelson et al. (2005) and Bartram et al. (2011) to identify the hedgers and nonhedgers: we used a number of keywords in searching hedging activities in the annual reports, which are as follows: "risk management", "hedging", "derivatives", “derivative financial instruments", "hedge accounting", "fair value 
hedging", "cash flow hedging", "net investment hedging", "risk exposure", "foreign currency risk", "interest rate risk", "commodity risk", "futures", "forwards", "options", "swaps", "floating rate", and "fixed rate". We also considered any comments reported under the derivative financial instruments disclosures that explain in detail the corporate hedging policies and activities.

For the hedgers, we gathered information on the hedging of the FX, IR and CM risks, with futures, forwards, options and swaps. We also collected data on the use of "other" derivatives but since they accounted for less than $1 \%$ of the total sample they were not considered in this paper. Our initial sample included 335 non-financial firms after dropping 305 financial firms from the index as of July 2018. In order to mitigate the survivorship bias, we included 60 delisted non-financial firms (for which we have the accounting data) to these existing non-financial firms, totalling 395 firms. In the UK financial markets, delisting companies from the index is subject to: 1) the monitoring mechanisms and regulations of the London Stock Exchange; 2) securities illiquidity that is being reviewed semi-annually and 3) mergers and acquisitions; noting that delisting is not necessarily related to corporate profitability. After the filtering related to inconsistent and extreme values and missing data, our final sample comprises information on 378 firms with 4,210 observations.

\subsection{Definition of variables}

This section presents the dependent and explanatory variables of our regression models. The Pearson correlation coefficients were not reported for brevity but they are available upon request. The variance inflation factors (VIFs) are far less than 10, suggesting the absence of multicollinearity problem in the models.

\subsubsection{Dependent variables}

We use return on assets (ROA) as a proxy for performance and Tobin's $Q$ as proxy for value following Allayannis and Weston (2001) and Pérez-González and Yun (2013), among others. ROA is earnings before finance costs and tax divided by total assets; Tobin's Q is total assets less book value of equity plus market value of equity divided by total assets. We also used return on invested capital (ROIC) as a proxy for performance, where ROIC is defined as earnings before finance costs and tax divided by the average of last year's and current year's total capital plus short-term debt and current portion of long-term debt. The results are quite similar and therefore, to save space, we do not report them. The distribution of Tobin's Q in our sample is skewed; hence, we use the logarithmic transformation for this variable. 


\subsubsection{Hedging-related explanatory variables}

Allayannis et al. (2012) show that hedging FX risk enhances value. Nelson et al. (2005) find little evidence that hedging IR risk is associated with abnormal market return. Jin and Jorion (2006) show that $\mathrm{CM}$ hedging is not necessarily positively associated with a market value premium. Panaretou (2014) finds that the presence of hedging activities and firm value are not correlated for the interest rate and commodity price risks but this correlation is significant and positive for currency hedging. The empirical literature, therefore, implies that the effect of hedging on firm outcomes depends on the risk type being hedged. These findings suggest the relevance of decomposition of risk types when studying this relationship. To account for this, we use a dummy variable $i$ ) which is 1 if firms hedge the FX risk in a given year; 0, otherwise; ii) which is 1 if firms hedge the IR risk; 0, otherwise; iii) which is 1 if firms hedge the CM risk; 0, otherwise.

\subsubsection{Control variables}

The literature shows that firm size can affect firm value (e.g., Lang and Stulz, 1994). We use the natural logarithm of total assets to measure size. We use the natural logarithm of the firm age since this factor has been shown to affect firm performance. Further, high investment growth may induce firms to hedge more (Froot et al., 1993; Géczy et al., 1997) and high investment growth implies higher firm value (Myers, 1977). We use capital expenditures to total assets and R\&D to total assets as proxies for investment growth opportunities and expect them to be positively associated with value and performance. Leland (1998) shows that increasing leverage reduces tax obligations and increases a managers' commitment to the firm. However, higher debt increases financial distress costs. Purnanandam (2008) finds a positive relationship between leverage and hedging if firms hold high financial distress costs. Allayannis and Weston (2001) include debt-equity ratio in their regression models and we use the proxy of total debt over total assets to control for the effect of financing mix. Aretz et al. (2007) and Bartram et al. (2009) find that dividend policy affects value and performance. Thus, another control factor that we adopt is a binary dummy variable indicating if firms pay dividends. If geographic diversification (GD) is implemented optimally it might enhance value and performance but it can also lead to overinvestment, eroding both value and performance (see, e.g., Lang and Stulz, 1994). Bodnar and Weintrop (1997), among others, find that GD is positively linked with value. We use a dummy variable to control for the effect of GD, which is 1 if firms have subsidiary outside the UK; 0, otherwise. Finally, the involvement of firms with hedging may be industry-related, as highlighted by Tufano (1996). We use the two-digit Standard Industrial Classification (SIC) codes to classify firms into nine groups. It is also reasonable to 
expect that exogenous factors that are time-varying would exert influence on firm outcomes. To account for such fixed effects, we use a set of industry and time dummies. Finally, we employ additional control factors as main risk and return variables for each risk type in order to account for the relevant market conditions, as shown in table A1 in the Appendix. These are Foreign currency return and Foreign currency volatility for the FX risk, Interest rate return and Interest rate volatility for the IR risk, and Commodity return and Commodity volatility for the CM risk.

\subsection{Descriptive analysis}

Table 1 Panel A provides summary statistics on hedging activities over the sample time period. It shows the percentage of hedgers and nonhedgers of the FX, IR and CM risks. Our results reveal that the proportion of hedgers has increased over time for the CM risk whereas for the IR and FX risks we observe some declining trend after 2011. More specifically, the percentage of firms that hedge the FX, IR and CM risks increased respectively from $67.0 \%, 60.4 \%$ and $13.5 \%$ in 2005 to $73.9 \%$, $64.0 \%$ and $17.5 \%$ in 2011 , respectively.

\section{[Please Insert Table 1 Here]}

Table 1 Panel B provides information on the use of various contracts. We report that forwards are most popular for hedging both the FX and the CM risks, and swaps are most popular for hedging the IR risk. More specifically, on average, for FX risk hedging, 66.9\% of the firms use forwards, $32.0 \%$ use swaps and $7.9 \%$ use options; futures are only marginally used, with less than $1 \%$. For the IR risk hedging, on average, $61.4 \%$ of the firms use swaps, $7.1 \%$ use options, and $4.4 \%$ use forwards; futures are again only very marginally used. For CM risk hedging, on average, 9.1\% of the firms use forwards, and $8.0 \%, 5.5 \%$ and $4.1 \%$ use swaps, options and futures, respectively.

Table 2 provides summary statistics for the full sample (panel A: hedging-related variables; panel B: explanatory and instrumental variables). It appears that $83.5 \%$ of our sample firms hedge for at least one risk type. For overall hedging regarding FX, IR and CM risks (i.e., firms hedging at least one of these risks), the mean value is $71.6 \%, 61.8 \%$ and $16.3 \%$, respectively. Our examination also shows that the percentages of the firms hedging FX, IR and CM risks only are $18.7 \%, 9.3 \%$ and $1 \%$, respectively. Similarly, we report that $14.1 \%$ (12.7\%) of the sample firms use forwards (swaps) only. As for the other variables, the mean values for Revenues, Total Assets and Market Value are $£ 4,328, £ 5,475$ and $£ 4,844$ million, respectively. The mean value for firm age is around 21 years. In addition, foreign sales represent $52.9 \%$ of the revenues, and the mean leverage is $21.9 \%$.

[Please Insert Table 2 Here] 


\section{The models and empirical findings}

\subsection{Regression models}

We study the effect of hedging the FX, IR and CM risks on value and performance, using the following regression model:

$$
Y_{i t}=\beta_{0}+\beta_{1} \operatorname{Hderiv}_{i t}+\theta X_{i t}^{\prime}+\varepsilon_{i t}
$$

where $\mathrm{Y}_{\text {it }}$ is ROA or Tobin's Q of firm $i$ in year $t$; Hderiv is one of the dummy variables which is 1 if firm $i$ hedges in year $t$ the FX, IR or CM risks with any of the contracts; 0 , otherwise; $\beta \mathrm{s}$ and $\theta \mathrm{s}$ are estimable parameters, $X^{\prime}{ }_{i t}$ is a vector of the control variables; and $\varepsilon_{i t}$ is the error term.

Our methods include TE, PSM and DDM analyses. More specifically, we use TE regressions to deal with self-selection bias, PSM technique to reduce the selection bias for our matched sample tests, and the DDM specification to provide and compare estimations across different time periods. The use of FU contracts for hedging the FX and IR risks are very marginal (accounting for less $1 \%$ of the total observations) and, therefore we omit these contracts from our regression analyses. Also, alternative to ROA, we use ROIC: as the regressions results are very similar we only report the ROA findings.

\subsection{Self-selection bias}

The prior analyses suggest that the effects of hedging FX, IR and CM risks with the use of financial derivatives on firm performance and value have mixed results. However, control variables such as firm size, capital structure, and geographic diversification are mainly selected in the presence of firms' categories that have been observed to implement corporate hedging strategy to mitigate financial risks. The effect of hedging financial risks on performance and value can come from other restrictions. For example, some firms are exposed to significant risks but they may not hedge to reduce such risks. Namely, it is plausible that hedgers or nonhedgers treat differently the value of corporate hedging. Therefore, an econometric concern arises when the dependent variable and explanatory variables appear related although the source of relationship is not the exogenous causality but self-selection bias, i.e., in essence they are not related. For example, it is possible that firms with high financial performance are likely to employ hedging strategies in order to keep their financial performance, which implies that the sampling is non-random and there is a potential simultaneity problem. To consider these issues, we utilize the TE method that can address potential 
self-selection bias. ${ }^{3}$ Therefore, we estimate the TE model for firm performance and value using the following setting.

$$
\begin{gathered}
Y_{i t}=\beta_{0}+\beta_{1} \text { Hderiv }_{i t}+\theta X_{i t}^{\prime}+\varepsilon_{i t} \\
\operatorname{Hderiv}_{i t}^{*}=\alpha_{0}+\alpha_{i t} Z_{i t}^{\prime}+\phi_{i t}
\end{gathered}
$$

where the observable decision (i.e., presence of hedging) denoted by Heriv $v_{\text {it }}$ is equal to one if the non-observable latent variable $H_{d e r i v_{i t}^{*}}>0$ and zero, otherwise; $\alpha_{0}$ is the constant term and $\alpha_{i}$ are the estimable parameters for the variables represented by the vector $Z$. We assume that the error terms $\phi_{\mathrm{it}}$ and $\varepsilon_{\mathrm{it}}$ have a normal bivariate distribution with mean zero and constant covariance matrix, and their correlation is quantified by $\rho$ (rho).

Table 3 - Panel A presents the TE results for firm performance. The coefficient for hedging FX risk in column 1 is positive but statistically insignificant. The TE findings in Table 3 further show that hedging FX risk with swap contracts are significantly and positively related to performance. As for the different contract types to hedge the CM risk, all the coefficient estimates are negative but only in the case of swaps do we see a significant association.

Table 3 Panel B presents the TE results for firm value. TE specifications have another clear consensus: the effect of overall FX (IR) hedging on value is significant and positive (negative) whereas for the overall effect of CM hedging we observe insignificant coefficients. ${ }^{4}$

The TE results show that any contract type to hedge the FX risk yields positive outcomes for the market value of the UK firms.

In sum, the results suggest that not all derivatives types would enhance value or improve performance. Moreover, whether financial risk management via derivatives generates value and good performance seems to depend on the type of the risk that is being managed. It maybe that some derivatives for hedging FX, IR or CM risk exposures are preferable to over-the-counter (OTC) in derivatives markets.

\section{[Please Insert Table 3 Here]}

\subsection{Matching}

In this section, related to the sample selection bias caused by non-randomness in deciding to use financial hedging instruments, we employ the PSM approach for further robustness. We first provide the details of the relevant estimation method before discussing the estimation results. 


\subsubsection{Propensity Score Matching (PSM) Method}

Following Rosenbaum and Rubin (1983) and Heckman et al. (1998), our Eq. (9) implies that estimating the conditional probability (i.e., propensity) of using derivatives is given by the function of $e\left(x_{i}\right)=\operatorname{prob}\left(z=1 \mid x_{i}\right)$.

$$
\operatorname{prob}\left(z_{1}, \ldots, z_{n} \mid x_{1}, \ldots, x_{n}\right)=\prod_{i=1}^{N} e\left(x_{i}\right)^{z_{i}}\left[1-e\left(x_{i}\right)\right]^{1-z_{i}}
$$

where $e(x)$ is the propensity score; $z_{i}$ is 1 if the firm is treated (i.e., used hedging) and 0 , if untreated; $x$ are the observed covariates based on the pre-treatment firm-specific characteristics that are likely to influence hedging decisions.

It is not possible to compare and match two firms that are internally identical other than having different preferences for hedging and under identical external conditions. Given this challenge, the main advantage of using the PSM setting is that it finds firms that are similar (not identical) except their choice for resorting to derivatives to hedge financial risk by calculating the non-hedgers' expected probability of using derivatives (i.e., instead of true propensity, the estimated propensity is used). Then, the matching is executed based on the highest similarity scores. PSM calculates the average difference between users vs. non-users of derivatives based on the matched sample's scores; the average estimation on the treatment model is the difference between the two counterfactual situations. In other terms, the observed difference in firm value or performance across all pairs can be considered as the robust estimate of the impact of derivatives' use. The PSM method first constructs a logit or probit model for the determinants of hedging financial risks and then predicts the outcome of performance and firm value with regards to derivatives effects. ${ }^{5}$ The use of the PSM method has been increasing in the related hedging literature (see e.g., Bartram et al., 2011; Chen and King, 2014).

Given the complexity of matching on covariates, the matching estimator we run is consistent under the generalized assumptions of the PSM method in order to estimate the average treatments effects of hedging financial risks for finite samples. Various specifications in the PSM approach (e.g., regression adjustment with or without inverse-probability weighting and nearest-neighbor matching) have recently been introduced to reduce bias in observational studies.

In our analysis, the functional options of the PSM procedure are based on the nearest-neighbor estimators for fixed numbers of matches for each observation when the samples of each type of risks and its related derivatives use are small (i.e., especially our commodity price risk sub-sample) (Busso et al., 2014). Motivated by Abadie and Imbens (2006), we adopt the PSM approach based on Abadie-Imbens standard errors (AI std) in predicting treatment assignment in the treatment model. We use this approach with its enhanced features with the conditioning that the propensity score is a 
balancing score (Rosenbaum and Rubin, 1983) to eliminate a potential bias in the inferences. The Abadie-Imbens specification minimizes the Mahalanobis distance between the vector of observed covariates for non-hedgers and hedgers: as the controls can be used more than once (i.e., multi matching with all tied observations) the estimation bias is reduced via a bias-correction component, compared to the matching without replacement. Abadie and Imbens produce robust standard errors to control for potential bias correction in the estimation that have advantages over weighting matching and bootstrap estimators.

In order to ensure the validity of the PSM results, two formal tests should be passed. The first one is called Common Support Condition (CSC) aka Overlap Test. The CSC examines the condition for each covariate that the probability of treating or not treating the observation is between zero and one, i.e., the treated observations are on support. There may be observations for which no match can be found within the specified caliper distance. Our PSM procedure with the nearest-neighbor matching approach drops such observations from the analysis and considers only the remaining subsample. The second test is Balancing Test (BT) or Independence Assumption which examines the difference in the means of the covariates between the control and treated groups to confirm that the matching procedure has eliminated significant differences across the groups. Our PSM results in this paper are robust to these tests (see figures A1 and A2 in the Appendix for the details). ${ }^{6,7}$

\subsubsection{The PSM estimations}

Table 4 Panel A shows the difference between hedgers and non-hedgers for three financial risks exposures in terms of value and performance using the PSM specification. The results suggest that the effect of hedging currency risk on firm value is positive and statistically significantly at the $1 \%$ level, which confirms our TE results. The matched firms in the users sample have higher firm value compared to the derivatives non-users peers: the differential effect between hedger vs. nonhedgers on firm value is 0.043 (in logarithmic transformation). However, for performance we do not observe a significant difference with a very small ROA differential effect of $0.3 \%$, which is in line with TE effects in table 3.

On the other hand, the impacts of hedging interest rate risk on performance and value are negative and statistically significantly at the $1 \%$ level, which again confirms our TE results. The corresponding differential effect between hedger vs. nonhedgers on firm performance and value with respect to the IR risk is $2.2 \%$ and 0.039 (in transformed values), respectively.

The PSM findings further show that the effect of hedging commodity price risk on performance is negative and statistically significant at the $1 \%$ level, and the magnitude of the differential effect is 
2\%; which are consistent with the corresponding TE results. Further, the differential effect on value is positive and significant at the $1 \%$ level with the magnitude of 0.076 ; noting that the corresponding TE results were insignificant.

Table 4 Panel $\mathrm{B}$ focuses on the types of derivatives in hedging currency risk. The results are significant and positive in all cases for firm value but insignificant when the focus is ROA. In Panel $\mathrm{C}$, we turn our attention to the derivatives for hedging IR risk: the differential effects on value and performance are negative and significant when options or swaps are used but when the forward contracts are used the effects become positive for both outcomes although sizeable $(5.4 \%, 0.061)$ yet insignificant.

Finally, the PSM results in Table 4 Panel D are related to hedging the CM risk with different contracts. The differential effects on performance are consistently negative and statistically significant at the $1 \%$ or $5 \%$ level for all contracts, which are generally in line with the TE results. Moreover, the differential effect on value is positive (negative) and significant at the $1 \%$ level for futures (forwards and swaps). As for the options, the differential effect on value is insignificant.

\section{[Please Insert Table 4 Here]}

\subsection{The effects of derivatives use across time periods}

The recent financial crisis tarnished the reputation of the financial markets and created the perception that derivatives might be harmful tools, supporting Warren Buffet's view that "derivatives are financial weapons of mass destruction". The question of whether the use of derivatives during, before or after financial crises enhances or impedes value or performance of firms relative to non-crisis or pre-crisis times is worth addressing. Particularly, one would need to consider the benefits and costs of hedging financial risks with derivatives during extraordinary times when high risk and uncertainty prevail. For instance, Bartram et al. (2011) find that during the economic downturn in 2001-2002 the usage of derivatives was associated with higher value and return. Similarly, in this paper we identify the differential impact of hedging on performance and value in times that include the financial crisis years (i.e., 2007-2009). Our goal in this sub-section is, therefore, to assess the effects of derivatives use across different time periods using the difference-in-differences (DiD) method with PSM (i.e., DDM). 


\subsubsection{The DDM method}

The empirical literature provides evidence based on the time series analysis of annual differences in dependent variables due to hedging financial risks in an attempt to unearth potential year-specific results. Relative changes in outcome variables due to the switching values of binary explanatory variables (i.e., derivatives use) could be assessed with interaction terms given a specific research hypothesis (see e.g., Chen and King, 2014). Furthermore, time series analysis is part of incremental value approach suggested by Faulkender and Wang (2006). In our paper, it is less appropriate to assess the incremental value or economic significance of binary explanatory variables (derivatives use dummy) on continuous outcome variables (performance or value) changes across time year-toyear differences

Alternatively, we adopt the DDM method that includes a treatment group (derivatives users) comparable with control group (non-users). This method compares the outcome of a sample of treatment firms vs. control firms in hedging financial risks by considering the possibility that the impact of exogenous factors on performance and value might vary across times that coincide with 'before, during and after' the 2007-2009 global financial crisis.

The DDM estimator developed by Heckman et al. (1997) is shown to be more effective than the conventional matching methods in bias-correction caused by the serial correlation. This specification addresses the econometric concerns related to omitted variables, non-observable firm characteristics and reverse causality (Fang et al., 2014) and used in the finance literature (Berger et al., 2014; Cheung et al., 2015). Consider the below equation:

$$
\theta_{\text {it }}=\mathrm{E}\left(\mathrm{Y}_{\mathrm{it}}\right)
$$

where $\mathrm{E}\left(\mathrm{Y}_{\mathrm{it}}\right)$ is the expected value for Tobin's Q or ROA; $i$ is 0 for the control (non-hedger) group, and it is 1 for the treated (hedger) group; $t$ is 0 for the pre-crisis period (2005-2007), and it is 1 for the post-crisis period (2008-2017) when the comparison is between the pre-crisis and post-crisis years; $t$ is 0 for the non-crisis years $(2005,2006,2010-2017)$ and it is 1 for the for the crisis period (2007-2009) when the comparison is between the crisis and non-crisis years. The standard 'differences' estimate regarding the role of hedging on the outcome for each sub-period is " $\theta_{11}-\theta_{01}$ " whereas the DDM estimate is " $\left(\theta_{11}-\theta_{01}\right)-\left(\theta_{10}-\theta_{00}\right)$ " that considers both the effect of exogenous shocks and hedging policy simultaneously. Examine also the regression model as shown below:

$$
Y_{i t}=\alpha_{0}+\alpha_{1} \text { Hderiv }_{i t}+\alpha_{2} \text { Time }_{t}+\alpha_{3}\left(\text { Hderiv }_{i t} * \text { Time }_{t}\right)+\beta Z_{i t}^{\prime}+\varepsilon_{i t}
$$


where $Y_{i t}$ represents the value or performance of firm $i$ in year $t$; Hderiv is an indicator variable that shows if the firm hedged against financial risk in a particular year; Time is an indicator variable that shows if the specific year coincides with the "post-crisis" period or "during-crisis" period as explained above. $Z^{\prime}{ }_{i t}$ is a set of explanatory variables as discussed in the previous sub-sections. $\beta$ 's and $\alpha$ 's are estimable parameters; $\varepsilon$ is the error term. Assessing Eq. (10) and Eq. (11) together, it can be shown via the probability limit (plim) formula that $\alpha_{0}=\theta_{00}$ (baseline average, i.e., no treatment and before period or no treatment and non-crisis years); $\alpha_{1}=\theta_{10}-\theta_{00}$ (the difference in means between hedgers and non-hedgers before the treatment); $\alpha_{2}=\theta_{01}-\theta_{00}$ (time trend or exogenous shocks impacting both groups after period); $\alpha_{3}=\left(\theta_{11}-\theta_{01}\right)-\left(\theta_{10}-\theta_{00}\right)$ (the overall DDM estimate as the difference in the changes over time after the treatment, i.e., our coefficient of interest that represents additional effect of the hedgers' mean value after the treatment). The two-tailed $t$ statistics examines the null hypothesis that the DDM estimators are zero.

\subsubsection{The DDM and PSM results across time periods}

Table 5 provides the PSM findings for the pre-crisis, post-crisis, during crisis and non-crisis periods whereas Table 6 reports the DDM results by comparing two periods at a time. ${ }^{8}$ For each model in Table 5, the coefficients capture the average treatment effects (ATE) of hedging on performance and value. In Table 6, on the other hand, the DDM method calculates the differences in the matched samples between the baseline period and the following period: i.e., the coefficients represent the difference between mean treatment difference between two time periods and mean control difference between two time periods. The focus of this paper regarding the crisis and stable years is on the latest global financial crisis. For robustness checks, we further examined the relevance of the European sovereign debt crisis period. The extant literature (e.g., Guney et al., 2017) posits that the European sovereign debt crisis period started in 2010 and we have not fully recovered from this most recent crisis. On the other hand, Acharya et al. (2018) restrict their crisis period to be between 2010 and 2012 due to their data set and their focus on the banking sector. Given that our focus is on corporate hedging for non-financial corporations, we construct an alternative definition to represent this crisis period from 2011 to 2014. As we do not find qualitatively different results based on this robustness check, we do not report the findings using the alternative definitions of pre-crisis, post-crisis, during crisis and non-crisis periods but they are available on request. 
Table 5 Panel A shows that having implemented FX hedging policies yielded incremental increase on value across all time-periods but for performance the incremental change is either insignificant or even significantly negative for the post-crisis period. As for the IR risk, consistent with the results based on the other methods, the incremental effects on value are negative and significant for all periods. Similarly, for performance, except the pre-crisis period, we again observe significantly negative net effects due to the IR risk hedging. On the other hand, implementing CM hedging policies had significantly negative incremental effects on performance in all time periods. Although we observe the same negative effects in the first three periods for value, it appears commodity price hedging has actually yielded positive incremental effects on firm value during the non-crisis years.

For ROA, the post-crisis effect (-0.031) is significantly higher in absolute terms than the insignificant pre-crisis effect (0.005) for the FX hedging. These findings imply that the incremental benefit of FX hedging during the pre-crisis years is almost zero but for the post-crisis years it is $3.1 \%$ lower compared to the other periods, which is statistically significant and economically sizeable. Therefore, one can contend that hedging for foreign currency risk after the latest global financial crisis has proved not beneficial with respect to financial performance. Related to this, the DDM coefficient of 0.010 in Table 6 Panel A suggests that the relative incremental benefit of FX hedging is $1 \%$ higher when it is conducted during the post-crisis times as opposed to the years before the crisis although this effect is statistically insignificant. For firm value in Table 5 Panel A, the pre-crisis effect (0.105) is significant and higher than the post-crisis effect (0.012) for the FX hedging. This finding implies that the incremental benefit of FX hedging during the pre-crisis years is 0.105 units higher and for the post-crisis years it corresponds to additional 0.012 units, which are statistically significant and economically sizeable. We can hence argue that hedging for foreign currency risk before the latest financial crisis has proved more beneficial as far as the firm value is concerned. On the other hand, the related DDM coefficient of 0.129 (Table 6 Panel A) implies that the relative incremental benefit of the FX hedging is 0.129 units higher when it is conducted after the crisis years as opposed to the years before the crisis and this difference is statistically significant and economically considerable.

\section{[Please Insert Table 5 Here]}

Table 5 Panel A also shows that the negative differential effect of FX hedging on ROA is lower during the crisis $(-0.004)$ compared to the non-crisis years $(-0.027)$. However, the related DDM 
coefficient of 0.028 in Table 6 Panel A implies that the relative incremental benefit of the FX hedging is $2.8 \%$ higher when it is adopted during the crisis years as opposed to the non-crisis years and this difference is statistically significant. In the same panel, the findings reveal that the positive incremental effect on firm value is higher when the FX hedging is conducted during the non-crisis years, i.e., 0.071 vs. 0.031. The corresponding DDM coefficient of 0.031 in Table 6 Panel A implies that the relative incremental effect of the FX hedging is 0.031 units higher when it is conducted during the crisis years as compared with the non-crisis years but this difference is statistically insignificant.

Table 5 Panel A further shows that the negative incremental effect of IR hedging on ROA is more apparent during the post-crisis times (-0.028) than during the pre-crisis period (0.008). The related DDM estimate in Table 6 Panel A is “-0.022", which suggests that the relative incremental effect of the IR hedging is $2.2 \%$ lower when it is adopted during the years following the crisis as opposed to the pre-crisis period and this difference is statistically significant. Furthermore, the negative incremental effect of IR hedging on ROA is less severe during the crisis times (-0.016) than during the non-crisis period (-0.021) and both estimates are statistically significant. The corresponding DDM estimate of " 0.030 " in Table 6 Panel A is statistically significant, suggesting that adopting IR-related hedging policies during the crisis did lead to additional benefits and this differential effect is material. Regarding the outcome of firm value, the magnitude of negative incremental effect for the IR risk hedging is higher during the pre-crisis period (-0.134) when compared to the post-crisis period (-0.056), and it is lower for the non-crisis years (-0.082) when compared to the crisis years (-0.093). Although these PSM estimates are statistically significant, the corresponding DDM estimates in Table 10 Panel A (i.e., - 0.021 and -0.026, respectively) are insignificant.

Moreover, Table 5 Panel A indicates that the incremental negative effect of CM hedging on ROA is more pronounced for the pre-crisis period (-0.056) relative to the post-crisis period $(-0.032)$, and it is less pronounced for the crisis years $(-0.026)$ relative to the non-crisis years $(-0.029)$. The corresponding DDM estimate the former is insignificant (i.e., -0.016) but it is significant and positive for the latter (i.e., 0.023) in Table 6 Panel A. When we examine the effect of CM hedging on value, the magnitude of the negative incremental effect of CM hedging on firm value is larger during the pre-crisis period (-0.143) when compared to the post-crisis period (-0.001). Interestingly, the same effect is larger and positive for the non-crisis period (0.063) when compared to the negative effect for the crisis years (-0.061). Although these PSM estimates are statistically 
significant, only one of the corresponding DDM estimates (i.e., -0.177) is significant in Table 6 Panel A.

For brevity, below we do not explain in detail the results for panels B, C and D of tables 5 and 6 which report the PSM and DDM estimates across different hedging contracts. The key findings in these panels are summarized as follows: $i$ ) the positive incremental effect of FX hedging on ROA in Table 5 Panel B is observed only when swaps are used during the crisis years; in other cases, the incremental effect is negative. However, the positive incremental effect of FX hedging on value creation is reported almost for all contracts especially the forwards across all time periods. Yet, the corresponding DDM estimates in Table 6 Panel B are statistically insignificant. ii) Table 5 Panel C shows that the overall negative incremental effect of IR hedging on ROA tends to observed across time and across all contracts, noting that the corresponding DDM estimates in Table 6 Panel $\mathrm{C}$ are significant only for options (i.e., -0.019). As for the IR hedging on firm value, options and swaps lead to negative incremental effects across all time periods, noting that the related DDM estimates in Table 6 Panel $\mathrm{C}$ are significant when during crisis and non-crisis years are compared (i.e., -0.202 and -0.124). iii) Table 5 Panel D reveals the overall negative incremental effect of CM hedging on ROA across various time periods appears to be originated from the use of forwards, options and swaps; yet, the respective DDM findings in Table 6 Panel D are generally insignificant. iv) Table 5 Panel D further reveals that the use of forwards for CM hedging across all time periods is associated with negative incremental effects, and for the other cases we report mixed evidence; noting also that the relevant DDM results in Table 6 Panel D are statistically significant only for the case of futures (i.e., 0.089 and -0.127 ).

Overall, once again, the effect of hedging on the value and performance of the listed UK firms varies depending on which financial risk they manage and which hedging instruments/contracts they are using. In addition, the findings of this sub-section suggest that the impact of hedging varies across time periods. It appears that firms benefit greatly from the use of only some type of derivatives before, during or after the crisis, which implies that corporate hedging strategies ought to be reviewed and updated as a reaction to the changes in the markets.

\section{[Please Insert Table 6 Here]}

Based on yearly data on the FTSE All share index listed firms over the period 2005-2017, our empirical analysis indicates the presence of a time varying financial risks (FX, IR and CM) 
exposure. We capture the time-varying patterns in market risks exposures by regressing the use of derivatives on firm value and performance as managers' decisions seem to find means of survival during difficult times. It is also explained as a result of a time-varying implied volatility factor for FX and IR and CM price risk.

\subsection{Additional analyses: hedging only one specific risk or using only one contract type}

In this sub-section, we provide some sensitivity analyses to distinguish firms that hedge single risk and use single derivatives contract from their peers hedging multiple risks via the use of multiple contracts. Table 7 reports the related TE results. We find that if the UK listed firms opt only for foreign currency hedging they improve their performance and market value. However, when they hedge only for interest rate fluctuations they reduce their ROA and firm value. On the other hand, our analyses show that hedging only for commodity price risk does not affect significantly these two firm outcomes. With regards to the derivatives contracts, using forwards (swaps) only for any risk seems to enhance (reduce) significantly financial performance and value of the UK firms. Yet, there is no significant association between hedging policy and firm value and performance for firms that use futures only or options only for any financial risk.

\section{[Please Insert Table 7 Here]}

Although corporate risk management theory suggests several ways through which corporate risk hedging can increase shareholders' value, the empirical evidence remains controversial with the detailed hedging instruments performance separately. It is possible that firms' hedging policy performance are also correlated with current market conditions, suggesting that managers' market views partially drive hedging instrument choices in favour of adding value to shareholders throughout hedging strategy announcements in events and detailed financial disclosures (e.g., financial crises, Brexit and political risks). Therefore, our empirical study shows overall mixed support to different types of contracts for rationales of hedging.

\section{Conclusion}

In this paper, we develop a theoretical and empirical analysis of the ambiguous (value-adding or value-destroying) effects of corporate risk-management (hedging/speculating), using derivatives, on firm value and performance. We provide two major contributions to the existing risk-management research. Firstly, our theoretical analysis demonstrates that corporate risk-management activities can add or destroy value, depending on a combination of economic (for example, managerial 
agency problems, managerial ability and risk aversion) and behavioural factors (managerial overconfidence). Secondly, having demonstrated theoretically the ambiguous nature of the relationship between hedging/speculating and firm value, we test this empirically. We examine the effects of hedging policies on the financial performance and value creation of non-financial UK firms during 2005-2017. Our empirical study rigorously analyses the effects of hedging various financial risks (foreign currency, interest rate and commodity price risks), using various derivative types (forwards, swaps, options, futures) on firm performance and value. Our in-depth empirical analysis confirms our theoretical analysis: that is, the effect of hedging, using derivatives is found empirically to be ambiguous (can be value-increasing or value-reducing, depending on the context). Closing the loop, our theoretical analysis provides some possible economic and behavioural explanations why managers may be involved in value-adding or value-reducing risk-management (hedging/speculation). In detail, our main empirical findings are summarised as follows:

First, the PSM technique finds that the matched firms in the FX hedgers sample have higher value compared to the non-hedgers, but the ROA differential effect is insignificant, and these results are valid for any contract. The effects of IR hedging on ROA and value are negative with significant differential contributions, and these results hold only for options and swaps. The impact of hedging $\mathrm{CM}$ risk on ROA (value) is negative (positive) with again significant differential effects; ROA results hold for all contracts but the finding for value creation is supported especially by futures.

Second, our PSM results across four time periods reveal that hedging policies have different effects on firm value and financial performance depending on the time period and the contract type. Among other results, the most salient PSM finding is that during the crisis times, we observe improvement in firm value only in the case of the foreign currency hedging. The DDM results suggest that the incremental positive effect on firm value is higher during post-crisis times relative to the pre-crisis times. Similarly, the DDM results further report that the negative effect of IR hedging on firm value is more apparent when forwards are used during crisis years relative to noncrisis years. Overall, our results suggest that IR hedging is beneficial when forwards are used and it is unrewarding when options and swaps are used.

Empirically, we have demonstrated the ambiguous relationship between hedging/speculation and firm value/performance: this relationship varies depending on the type of risk, the type of derivatives employed, and the time period. This clearly warrants some further and deeper research to unearth the underlying reasons for these varying effects. In this paper, we have begun this task by developing a theoretical model that analyses the effect of various economic and behavioural factors 
on managerial motives for hedging/speculation. Our theoretical model analyses hedging/speculation generally without consideration of specific derivative instruments, or types of risk. For future research it would be desirable to develop the model further to consider the effect of individual derivatives, and risk-types. Such analyses would aid deeper understanding of our mixed empirical results for the effect of hedging using the varying types of derivatives on firm value.

We note that our theoretical and empirical analysis has implications for academics and practitioners alike. For academics, we have provided a deep theoretical framework that provides an economic and behavioural rationale as to why the relationship between corporate hedging/speculation and firm value/firm performance may be ambiguous (may be value-increasing or value-reducing). Therefore, it would be desirable for researchers conducting future empirical analysis of the relationship between corporate hedging and firm value to disentangle the economic effects of managerial self-interested moral hazard, risk-aversion, and perception of financial distress costs from the behavioural effects of overconfidence: particularly, our model predicts that an increase in managerial self-interested moral hazard, managerial risk aversion/caution, and perceived financial distress costs, may lead to more (possibly value-reducing) hedging, while managerial overconfidence may result in more speculative use of derivatives (with an ambiguous effect on firm value).

Furthermore, our theoretical analysis emphasises that derivative-usage in risk-management can be a ' double-edged sword.' Derivatives can be used to hedge (reduce risk) or speculate (increase risk). Our theoretical model demonstrates that managers may have incentives to use derivatives to conduct either of these policies. When examining empirically, it may not be sufficient merely to examine the amount or extent of derivative-usage in risk management. It is important to attempt to understand (perhaps by reading the narratives in the financial statements) why derivatives are being used (to hedge or to speculate).

For corporate managers and policy-makers, our analysis is important, as it demonstrates that the use of derivatives in risk-management does not always add value: the firm may actually be involved in 'bad hedging', reducing shareholder value. Managers are not always aligned with shareholders in their decision-making. It might therefore be desirable to address agency problems, as well as managers' caution, natural risk aversion, and anxiety relating to financial distress. This may involve economic incentives, such as enhanced equity stakes, or managerial stock options, and economic 
threats and punishments for bad decisions, as well as enhanced monitoring of managerial riskmanagement behaviour.

However, even if corporate managers believe that they are acting in shareholders' interests, there may be behavioural/psychological reasons why management may be engaged in 'bad hedging'. The behavioural corporate finance approach emphasises that bad decisions can result from psychological errors and mistakes, rather than managerial moral hazard/agency problems. As the literature argues, in this case, economic incentives and punishments may not work to correct bad managerial decisions. Now, coaching, education, mindfulness and managerial self-awareness may be important. In our model, overconfidence results in an excessive use of value-reducing use of derivatives for speculation. However, managerial anxiety can drive them towards excessive valuereducing hedging. Perhaps, managers should receive enhanced training and self-awareness courses to achieve objectivity in their risk-management strategies.

Finally, in the wake of recent efforts to regulate derivatives markets, our results are especially timely, given the changes in monitoring risk-hedging activities currently under consideration by policy-makers, particularly for financial derivatives. Regulators could use our theoretical and empirical results to design optimal regulations.

\section{References}

Abadie, A., and Imbens, G.W. (2006). Large sample properties of matching estimators for average treatment effects. Econometrica, 74(1), 235-267.

Acharya, V.V., Eisert, T., Eufinger, C. and Hirsch, C. (2018). Real effects of the sovereign debt crisis in Europe: evidence from syndicated loans. Review of Financial Studies, 31(8), 2855-2896.

Adam, T.R., and Fernando, C.S. (2006). Hedging, speculation, and shareholder value. Journal of Financial Economics, 81(2), 283-309.

Adam, T.R., Fernando, C.S. and Salas, J.M. (2017). Why do firms engage in selective hedging? Evidence from the gold mining industry. Journal of Banking and Finance, 77, 269-282.

Allayannis, G., Lel, U., and Miller, D. P. (2012). The use of foreign currency derivatives, corporate governance, and firm value around the world. Journal of International Economics, 87(1), 65-79.

Allayannis, G., and Weston, J. P. (2001). The use of foreign currency derivatives and firm market value. Review of Financial Studies, 14(1), 243-276.

Aretz, K., and Bartram, S. M. (2010). Corporate hedging and shareholder value. Journal of Financial Research, 33(4), 317-371.

Aretz, K., Bartram, S. M., and Dufey, G. (2007). Why hedge? Rationales for corporate hedging and value implications. Journal of Risk Finance, 8(5), 434-449.

Bartram, S. M., and Bodnar, G. M. (2007). The exchange rate exposure puzzle. Managerial Finance, 33(9), 642666.

Bartram, S. M., Brown, G. W., and Conrad, J. (2011). The effects of derivatives on firm risk and value. Journal of Financial and Quantitative Analysis, 46(4), 967-999.

Bartram, S. M., Brown, G. W., and Fehle, F. R. (2009). International evidence on financial derivatives usage. Financial Management, 38(1), 185-206. 
Berger, A. N., Kick, T., and Schaeck, K. (2014). Executive board composition and bank risk taking. Journal of Corporate Finance, 28, 48-65.

Bessembinder, H. (1991). Forward contracts and firm value: Investment incentive and contracting effects. Journal of Financial and Quantitative Analysis, 26(4), 519-532.

Bodnar, G. M., Consolandi, C., Gabbi, G., and Jaiswal-Dale, A. (2013). Risk Management for Italian Non-Financial Firms: Currency and Interest Rate Exposure. European Financial Management, 19(5), 887-910.

Bodnar, G. M., and Weintrop, J. (1997). The valuation of the foreign income of US multinational firms: A growth opportunities perspective. Journal of Accounting and Economics, 24(1), 69-97.

Bonaimé, A. A., Hankins, K. W., and Harford, J. (2014). Financial flexibility, risk management, and payout choice. Review of Financial Studies, 27(4), 1074-1101.

Borokhovich, K. A., Brunarski, K. R., Crutchley, C. E., and Simkins, B. J. (2004). Board composition and corporate use of interest rate derivatives. Journal of Financial Research, 27(2), 199-216.

Breeden, D.T. and Viswanathan, S. (2016). Why do firms hedge? An asymmetric information model, Journal of Fixed Income, 25(3), 125.

Busso, M., DiNardo, J., and McCrary, J. (2014). New evidence on the finite sample properties of propensity score reweighting and matching estimators. Review of Economics and Statistics, 96(5), 885-897.

Carter, D. A., Rogers, D. A., and Simkins, B. J. (2006). Hedging and value in the US airline industry. Journal of Applied Corporate Finance, 18(4), 21-33.

Chang, E. C., and Wong, K. P. (2003). Cross-hedging with currency options and futures. Journal of Financial and Quantitative Analysis, 38(3), 555-574.

Chen, J., and King, T.-H. D. (2014). Corporate hedging and the cost of debt. Journal of Corporate Finance, 29, 221-245.

Chen, Y. (2011). Derivatives use and risk taking: Evidence from the hedge fund industry. Journal of Financial and Quantitative Analysis, 46(4), 1073-1106.

Chernenko, S., and Faulkender, M. (2011). The two sides of derivatives usage: Hedging and speculating with interest rate swaps. Journal of Financial and Quantitative Analysis, 46(6), 1727-1754.

Cheung, W. M., Chung, R., and Fung, S. (2015). The effects of stock liquidity on firm value and corporate governance: Endogeneity and the REIT experiment. Journal of Corporate Finance, 35, 211-231.

Dhanani, A., Fifield, S., Helliar, C., and Stevenson, L. (2007). Why UK companies hedge interest rate risk. Studies in Economics and Finance, 24(1), 72-90.

Fang, V. W., Tian, X., and Tice, S. (2014). Does stock liquidity enhance or impede firm innovation? Journal of Finance, 69(5), 2085-2125.

Faulkender, M. (2005). Hedging or market timing? Selecting the interest rate exposure of corporate debt. Journal of Finance, 60(2), 931-962.

Faulkender, M., and Wang, R. (2006). Corporate financial policy and the value of cash. Journal of Finance, 61(4), 1957-1990.

Fauver, L., and Naranjo, A. (2010). Derivative usage and firm value: The influence of agency costs and monitoring problems. Journal of Corporate Finance, 16(5), 719-735.

Froot, K. A., Scharfstein, D. S., and Stein, J. C. (1993). Risk management-coordinating corporate-investment and financing policies. Journal of Finance, 48(5), 1629-1658.

Géczy, C. C., Minton, B. A., and Schrand, C. M. (2007). Taking a view: corporate speculation, governance, and compensation. Journal of Finance, 62(5), 2405-2443.

Géczy, C., Minton, B. A., and Schrand, C. (1997). Why firms use currency derivatives. Journal of Finance, 52(4), 1323-1354.

Guney, Y., Karpuz, A. and Ozkan, N., (2017). R\&D investments and credit lines. Journal of Corporate Finance, 46, 261-283.

Heckman, J. J., Ichimura, H., and Todd, P. E. (1997). Matching as an econometric evaluation estimator: Evidence from evaluating a job training programme. Review of Economic Studies, 64(4), 605-654.

Jin, Y., and Jorion, P. (2006). Firm value and hedging: evidence from US oil and gas producers. Journal of Finance, 61(2), 893-919.

Lang, L. H. P., and Stulz, R. M. (1994). Tobin's Q, corporate diversifications, and firm performance. Journal of Political Economy, 102, 1248-1280.

Leland, H. E. (1998). Agency costs, risk management, and capital structure. Journal of Finance, 53(4), 12131243.

MacKay, P., and Moeller, S. B. (2007). The value of corporate risk management. Journal of Finance, 62(3), 13791419. 
Marami, A., and Dubois, M. (2013). Interest rate derivatives and firm value: evidence from mandatory versus voluntary hedging. SSRN Working Paper.

Modigliani, F., and Miller, M. (1958). The cost of capital, corporate finance and the theory of investment. American Economic Review, 48(3), 261-297.

Myers, S.C. (1977). Determinants of corporate borrowing. Journal of Financial Economics, 5(2), 147-175.

Nelson, J. M., Moffitt, J. S., and Affleck-Graves, J. (2005). The impact of hedging on the market value of equity. Journal of Corporate Finance, 11(5), 851-881.

Panaretou, A. (2014). Corporate risk management and firm value: evidence from the UK market. European Journal of Finance, 20(12), 1161-1186.

Pérez-González, F., and Yun, H. (2013). Risk management and firm value: evidence from weather derivatives. Journal of Finance, 68(5), 2143-2176.

Purnanandam, A. (2008). Financial distress and corporate risk management: theory and evidence. Journal of Financial Economics, 87(3), 706-739.

Rosenbaum, P. R., and Rubin, D. B. (1983). The central role of the propensity score in observational studies for causal effects. Biometrika, 70(1), 41-55.

Smith, C. W., and Stulz, R. M. (1985). The determinants of firms' hedging policies. Journal of Financial and Quantitative Analysis, 20(4), 391-405.

Tufano, P. (1996). Who manages risk? An empirical examination of risk management practices in the gold mining industry. Journal of Finance, 51(4), 1097-1137. 


\section{Appendix}

Table A1.

The definition of variables

\begin{tabular}{|c|c|c|}
\hline Variable & Definition & Data Source \\
\hline \multicolumn{3}{|l|}{ Derivatives use: } \\
\hline$\overline{\text { Hedging decisions }}$ & Dummy variable with value 1 if firms use derivative securities for hedging FX, IR or CM risks, and 0 otherwise. & Annual report \\
\hline Foreign currency hedge & Dummy variable with value 1 if firms use derivative securities for hedging FX risk, and 0 otherwise. & Annual report \\
\hline Foreign currency futures & Dummy variable with value 1 if firms use futures contracts for hedging FX risk, and 0 otherwise. & Annual report \\
\hline Foreign currency forwards & Dummy variable with value 1 if firms use forward contracts for hedging FX risk, and 0 otherwise. & Annual report \\
\hline Foreign currency options & Dummy variable with value 1 if firms use option contracts for hedging FX risk, and 0 otherwise. & Annual report \\
\hline Foreign currency swaps & Dummy variable with value 1 if firms use swap contracts for hedging FX risk, and 0 otherwise. & Annual report \\
\hline Interest rate hedge & Dummy variable with value 1 if firms use derivative securities for hedging IR risk, and 0 otherwise. & Annual report \\
\hline Interest rate futures & Dummy variable with value 1 if firms use futures contracts for hedging IR risk, and 0 otherwise. & Annual report \\
\hline Interest rate forwards & Dummy variable with value 1 if firms use forward contracts for hedging IR risk, and 0 otherwise. & Annual report \\
\hline Interest rate options & Dummy variable with value 1 if firms use option contracts for hedging IR risk, and 0 otherwise. & Annual report \\
\hline Interest rate swaps & Dummy variable with value 1 if firms use swap contracts for hedging IR risk, and 0 otherwise. & Annual report \\
\hline Commodity price hedge & Dummy variable with value 1 if firms use derivative securities for hedging CM risk, and 0 otherwise. & Annual report \\
\hline Commodity futures & Dummy variable with value 1 if firms use futures contracts for hedging $\mathrm{CM}$ risk, and 0 otherwise. & Annual report \\
\hline Commodity forwards & Dummy variable with value 1 if firms use forward contracts for hedging CM risk, and 0 otherwise. & Annual report \\
\hline Commodity options & Dummy variable with value 1 if firms use option contracts for hedging CM risk, and 0 otherwise. & Annual report \\
\hline Commodity swaps & Dummy variable with value 1 if firms use swap contracts for hedging CM risk, and 0 otherwise. & Annual report \\
\hline Foreign currency only & Dummy variable with value 1 if firms use derivative securities for hedging FX risk only, and 0 otherwise. & Annual report \\
\hline Interest rate only & Dummy variable with value 1 if firms use derivative securities for hedging IR risk only, and 0 otherwise. & Annual report \\
\hline Commodity price only & Dummy variable with value 1 if firms use derivative securities for hedging CM risk only, and 0 otherwise. & Annual report \\
\hline Futures only & Dummy variable with value 1 if firms use futures contracts only for hedging FX, IR or CM risks, and 0 otherwise. & Annual report \\
\hline Forwards only & Dummy variable with value 1 if firms use forwards contracts only for hedging FX, IR or CM risks, and 0 otherwise. & Annual report \\
\hline Options only & Dummy variable with value 1 if firms use options contracts only for hedging FX, IR or CM risks, and 0 otherwise. & Annual report \\
\hline Swaps only & Dummy variable with value 1 if firms use swaps contracts only for hedging FX, IR or CM risks, and 0 otherwise. & Annual report \\
\hline \multicolumn{3}{|c|}{ ( } \\
\hline Revenues & Total revenues (or net sales) of the firm & Bloomberg \\
\hline Total Assets & Total assets of the firm & Bloomberg \\
\hline Return on Assets & Earnings before finance costs and tax / book value of total assets. & Bloomberg \\
\hline Net income & Net income after depreciation, interest, taxes and other expenses. & Bloomberg \\
\hline Firm Market Value & The share price of the company's stock at its fiscal year end multiplied by the number of common shares outstanding. & Bloomberg \\
\hline Tobin's Q (ln) & Ln [(total assets - book value of equity + market value of equity $) /$ total assets $]$ & Bloomberg \\
\hline Firm Size & Natural logarithm of the book value of total assets in 2005 prices. & Bloomberg \\
\hline Firm Age (ln) & Natural logarithm of the number of years since the stock of the firm first appears in London Stock Exchange (LSE). & Annual report \\
\hline Leverage & Book value of total debt, including short and long debt / book value of total assets. & Bloomberg \\
\hline Dividends per share & Total dividends paid divided by the number of shares (in pence). & Bloomberg \\
\hline Dividends dummy & Dummy variable with value of 1 if DPS is greater than zero, and 0 , otherwise. & Bloomberg \\
\hline Capex/assets & Capital expenditures divided by book value of assets. & Bloomberg \\
\hline $\mathrm{R} \& \mathrm{D} / \mathrm{assets}$ & Research and development expense divided by book value of assets. & Bloomberg \\
\hline \multicolumn{3}{|l|}{ Instrumental variables: } \\
\hline $\begin{array}{l}\text { Geographic } \\
\text { Diversification }\end{array}$ & Dummy variable with value 1 if firms have subsidiaries outside the UK, and 0 otherwise. & Bloomberg \\
\hline Foreign Sales Ratio & The ratio of foreign sales to revenues (or net sales). & Annual report \\
\hline Foreign Expenditures & Dummy variable with value 1 if firms have foreign expenditures abroad, and 0 otherwise. & Annual report \\
\hline Floating Rate Debt & Dummy variable with value 1 if firm has borrowings debt in floating interest rate. & Annual report \\
\hline Fixed Rate Debt & Dummy variable with value 1 if firm has borrowings debt in fixed interest rate. & Annual report \\
\hline Commodity Purchases & Dummy variable with value 1 if firms buy commodity for use in operations, and 0 otherwise. & Annual report \\
\hline Commodity Oil and Gas & Dummy variable with value 1 if firms sell or produce oil, gas or mining related commodities, and 0 otherwise. & Annual report \\
\hline \multicolumn{3}{|l|}{ Main risk variables: } \\
\hline Foreign currency return & $\begin{array}{l}\text { Annual rate of return based on the average value of the monthly effective exchange rate index for } £ \text {, calculated at the } \\
\text { end of each year and lagged by one year. }\end{array}$ & Bloomberg \\
\hline Foreign currency volatility & $\begin{array}{l}\text { Standard deviation of the average value of the monthly effective exchange rate index for } £ \text { over the last twelve months, } \\
\text { calculated at the end of each year and lagged by one year. }\end{array}$ & Bloomberg \\
\hline Interest rate return & Annual rate of return based on the UK 10 Year Gilt Yield, calculated at the end of each year and lagged by one year. & Bloomberg \\
\hline Interest rate volatility & $\begin{array}{l}\text { Standard deviation of the UK } 10 \text { Year Gilt Yield over the last twelve months, calculated at the end of each year and } \\
\text { lagged by one year. }\end{array}$ & Bloomberg \\
\hline Commodity return & $\begin{array}{l}\text { Annual rate of return based on the Thomson Reuters Core Commodity CRB Index which comprises a basket of } 19 \\
\text { commodities, with } 39 \% \text { allocated to energy contracts, } 41 \% \text { to agriculture, } 7 \% \text { to precious metals and } 13 \% \text { to industrial } \\
\text { metals, calculated at the end of each year and lagged by one year. }\end{array}$ & $\begin{array}{l}\text { Reuters } \\
\text { EIKON }\end{array}$ \\
\hline Commodity volatility & $\begin{array}{l}\text { Standard deviation of the Thomson Reuters Core Commodity CRB Index over the last twelve months, calculated at the } \\
\text { end of each year and lagged by one year. }\end{array}$ & $\begin{array}{l}\text { Reuters } \\
\text { EIKON }\end{array}$ \\
\hline
\end{tabular}


Table A2.

Summary of the findings of our theoretical model

\begin{tabular}{|c|c|c|c|}
\hline \multicolumn{4}{|c|}{ Panel A: High true ability of managers } \\
\hline $\begin{array}{l}\text { Financial Distress/ } \\
\text { Overconfidence }\end{array}$ & Low & Medium & High \\
\hline Low & Speculative: first-best & Speculative: first-best & Speculative: first-best \\
\hline Medium & Hedging: inefficient & Speculative: first-best & Speculative: first-best \\
\hline High & Hedging: inefficient & Hedging: inefficient & Speculative: first-best \\
\hline Very High & Hedging: inefficient & Hedging: inefficient & Hedging: inefficient \\
\hline \multicolumn{4}{|c|}{ Panel B: Low true ability of managers } \\
\hline $\begin{array}{l}\text { Financial Distress/ } \\
\text { Overconfidence }\end{array}$ & Low & Medium & High \\
\hline Low & Speculative: inefficient & Speculative: inefficient & Speculative: inefficient \\
\hline Medium & Hedging: first-best & Speculative: inefficient & Speculative: inefficient \\
\hline High & Hedging: first-best & Hedging: first-best & Speculative: inefficient \\
\hline Very High & Hedging: first-best & Hedging: first-best & Hedging: first-best \\
\hline
\end{tabular}


Figure A1.

Diagnostics tests for the PSM results: firm performance and financial risks

(i) Firm performance and FX risk
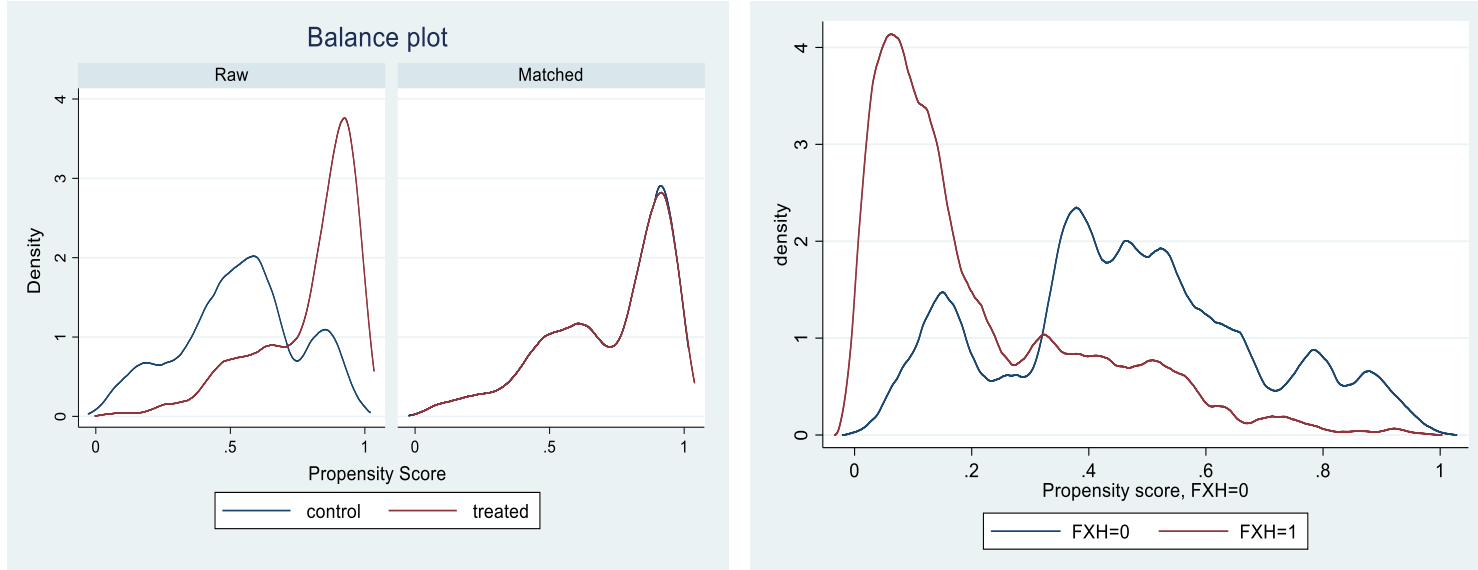

(ii) Firm performance and IR risk
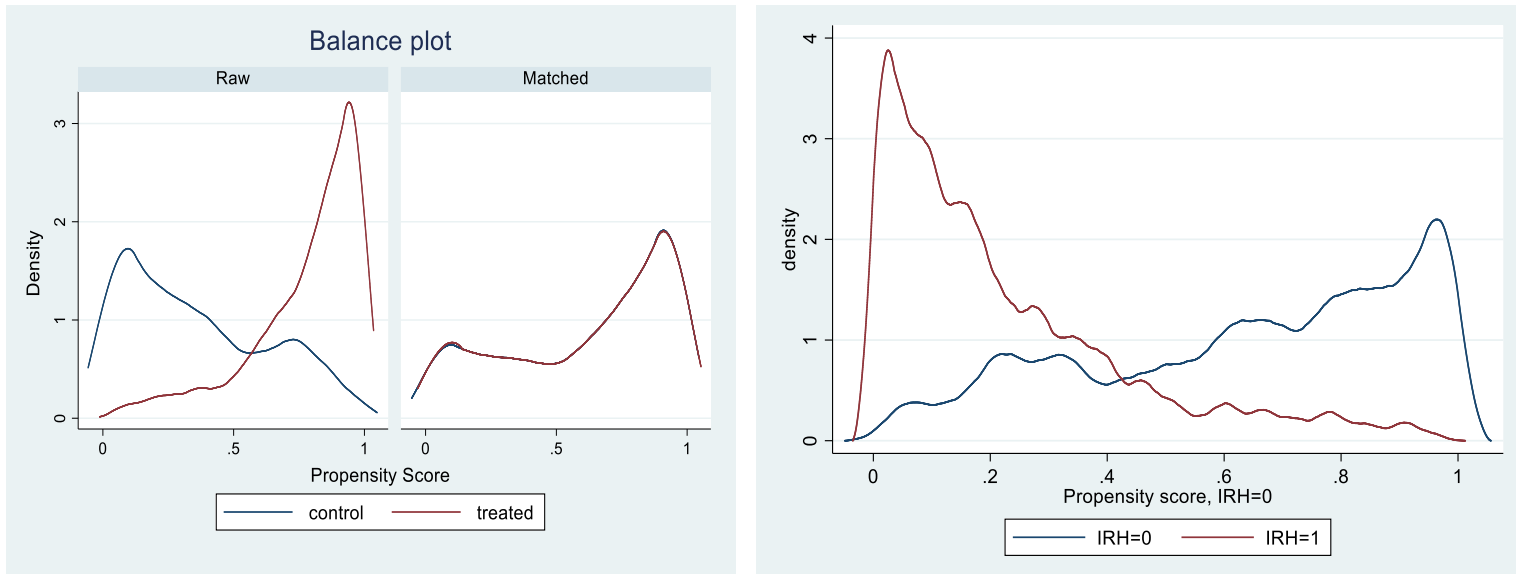

(iii) Firm performance and CM risk
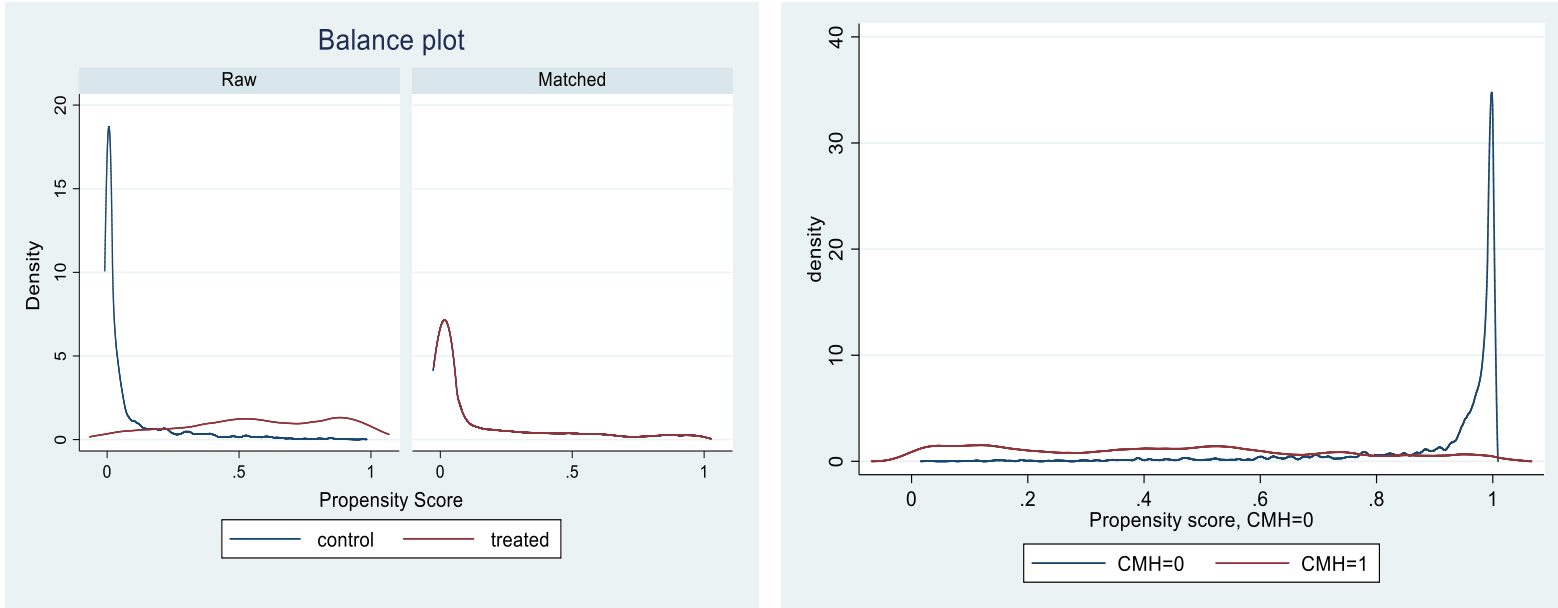
Figure A2.

Diagnostics tests for the PSM results: firm value and financial risks

(i) Firm value and FX risk
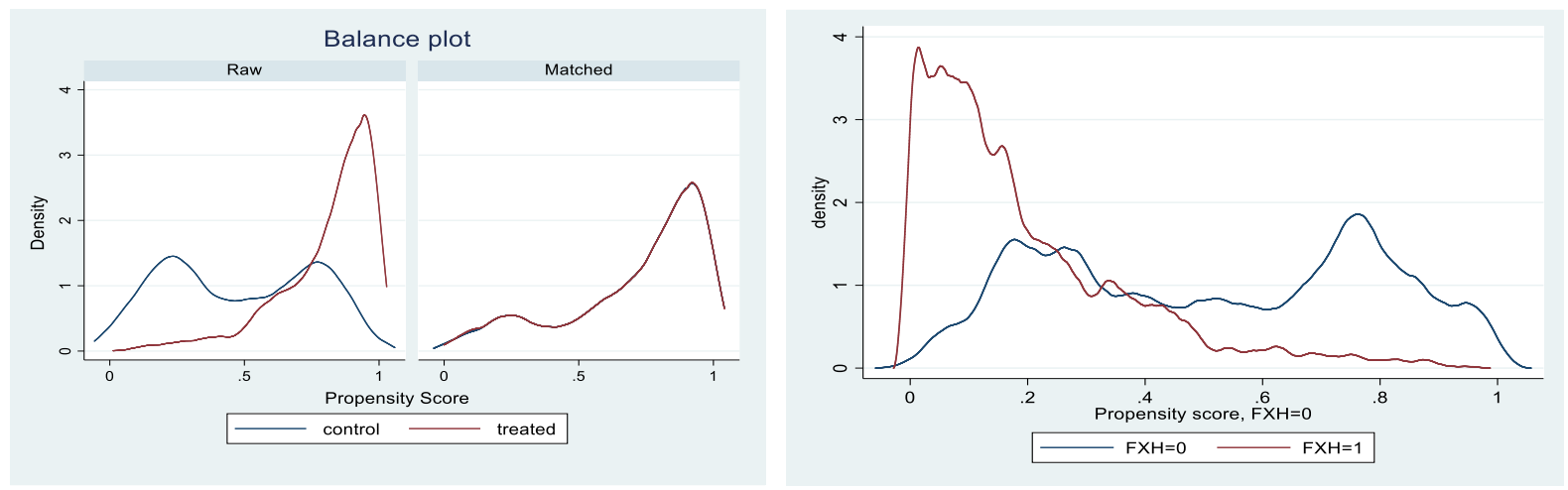

(ii) Firm value and IR risk
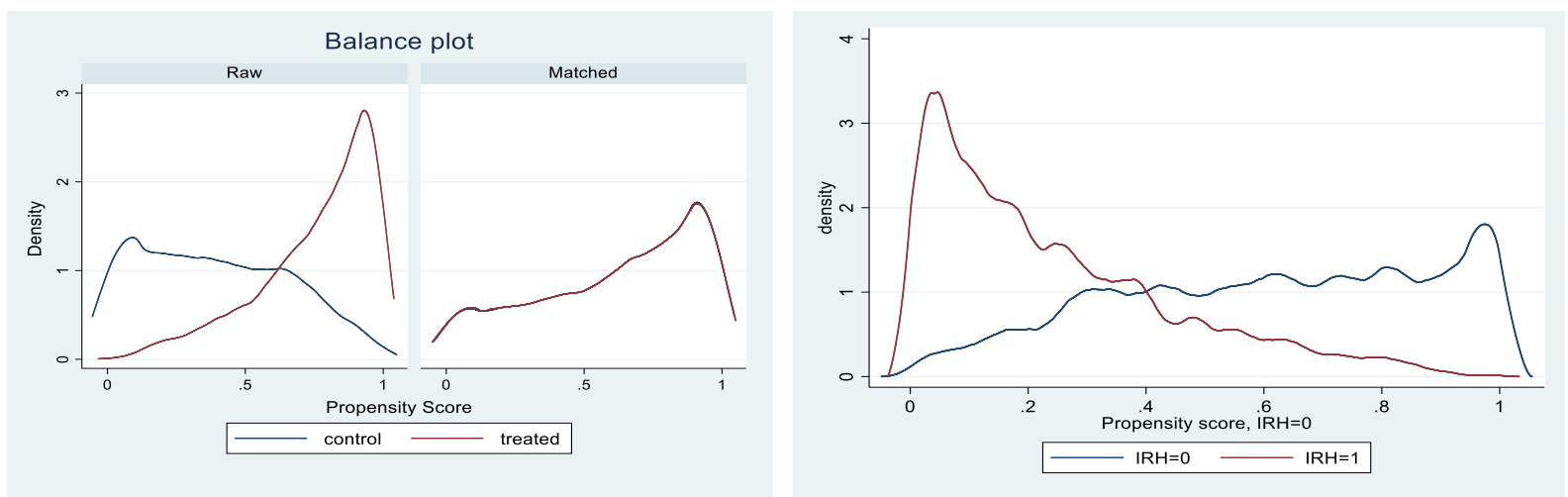

(iii) Firm value and CM risk
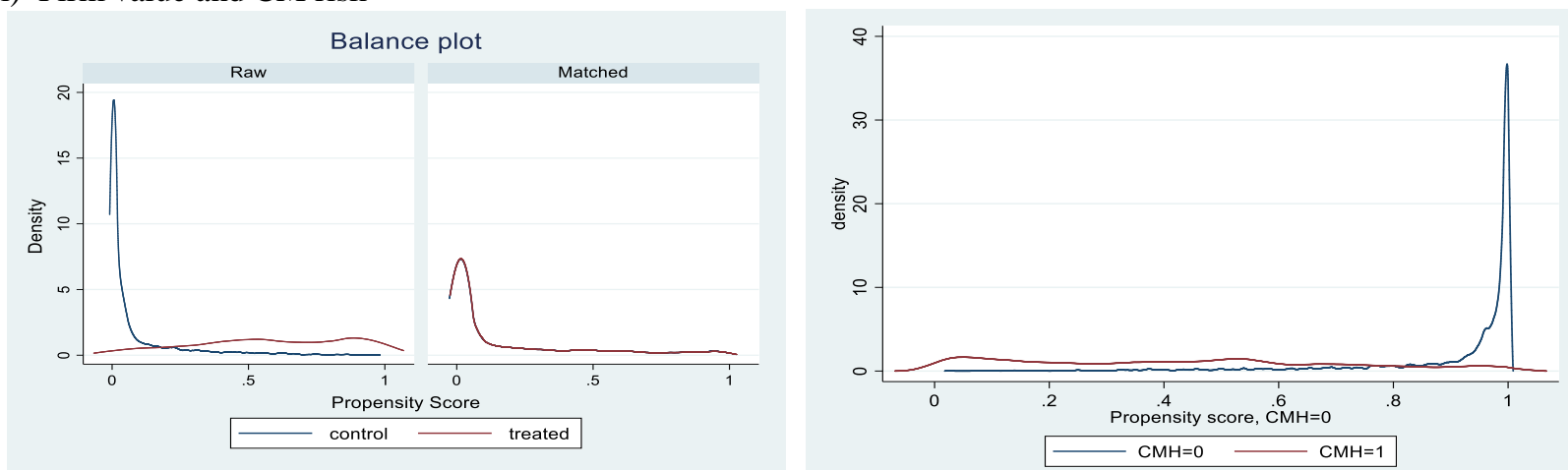

Figure A1 and Figure A2 provide the balance and overlap tests for the PSM method for performance and value, respectively, in line with the overall financial risks exposures (FX, IR and CM) as reported in Table 6 Panel A, using the advanced Stata options (i.e., caliper, pstolerance and nneighbor) (Abadie and Imbens, 2006; Rosenbaum and Rubin, 1983). The balance tests on the left-hand side plots of both figures show that matching process provided good balance in the covariate distributions in the treated and control groups. The plots on the right-hand side reveal that the overlap tests are satisfactory, except for the sub-sample of hedging for the CM risk where the probability mass tends to be near 0 . The issue with the CM risk may stem from the relatively small sample size: i.e., it has 687 observations compared to 3,015 and 2,602 observations for the FX and IR risks, respectively. However, our approach for such sub-samples is consistent with the common support limitation when finite sample in specific type of variables is limited during the matching process and also we imposed advanced options to ensure this critical assumption is passed in our tests. The CM risks-related results may still be interpreted with caution. Overall, the two diagnostics tests (i.e., overlap and balancing tests) related to these figures suggest that our PSM results are valid because i) the treated observations are on support and ii) there is no difference between the control and treated groups as per the covariates. 
Table 1

Sample firms and hedging behaviour by contract type and years

\begin{tabular}{|c|c|c|c|c|c|c|c|c|c|c|c|c|}
\hline \multicolumn{13}{|c|}{ Panel A: Hedging financial risks by year } \\
\hline & \multicolumn{4}{|c|}{ Foreign currency hedging } & \multicolumn{4}{|c|}{ Interest rate hedging } & \multicolumn{4}{|c|}{ Commodity price hedging } \\
\hline & $\mathrm{H}>0$ & $\%$ & $\mathrm{H}=0$ & $\%$ & $\mathrm{H}>0$ & $\%$ & $\mathrm{H}=0$ & $\%$ & $\mathrm{H}>0$ & $\%$ & $\mathrm{H}=0$ & $\%$ \\
\hline 2005 & 193 & $67.0 \%$ & 95 & $33.0 \%$ & 174 & $60.4 \%$ & 114 & $39.6 \%$ & 39 & $13.5 \%$ & 249 & $86.5 \%$ \\
\hline 2006 & 202 & $68.2 \%$ & 94 & $31.8 \%$ & 178 & $60.1 \%$ & 118 & $39.9 \%$ & 42 & $14.2 \%$ & 254 & $85.8 \%$ \\
\hline 2007 & 215 & $70.3 \%$ & 91 & $29.7 \%$ & 191 & $62.4 \%$ & 115 & $37.6 \%$ & 43 & $14.1 \%$ & 263 & $86.0 \%$ \\
\hline 2008 & 224 & $72.0 \%$ & 87 & $28.0 \%$ & 196 & $63.0 \%$ & 115 & $37.0 \%$ & 53 & $17.0 \%$ & 258 & $83.0 \%$ \\
\hline 2009 & 230 & $73.0 \%$ & 85 & $27.0 \%$ & 202 & $64.1 \%$ & 113 & $35.9 \%$ & 51 & $16.2 \%$ & 264 & $83.8 \%$ \\
\hline 2010 & 234 & $72.7 \%$ & 88 & $27.3 \%$ & 206 & $64.0 \%$ & 116 & $36.0 \%$ & 50 & $15.5 \%$ & 272 & $84.5 \%$ \\
\hline 2011 & 240 & $73.9 \%$ & 85 & $26.2 \%$ & 208 & $64.0 \%$ & 117 & $36.0 \%$ & 57 & $17.5 \%$ & 268 & $82.5 \%$ \\
\hline 2012 & 242 & $73.6 \%$ & 87 & $26.4 \%$ & 202 & $61.4 \%$ & 127 & $38.6 \%$ & 56 & $17.0 \%$ & 273 & $83.0 \%$ \\
\hline 2013 & 247 & $73.3 \%$ & 90 & $26.7 \%$ & 212 & $62.9 \%$ & 125 & $37.1 \%$ & 58 & $17.2 \%$ & 279 & $82.8 \%$ \\
\hline 2014 & 249 & $72.0 \%$ & 97 & $28.0 \%$ & 212 & $61.3 \%$ & 134 & $38.7 \%$ & 58 & $16.8 \%$ & 288 & $83.2 \%$ \\
\hline 2015 & 250 & $71.4 \%$ & 100 & $28.6 \%$ & 214 & $61.1 \%$ & 136 & $38.9 \%$ & 62 & $17.7 \%$ & 288 & $82.3 \%$ \\
\hline 2016 & 251 & $71.9 \%$ & 98 & $28.1 \%$ & 208 & $59.6 \%$ & 141 & $40.4 \%$ & 60 & $17.2 \%$ & 289 & $82.8 \%$ \\
\hline 2017 & 238 & $70.8 \%$ & 98 & $29.2 \%$ & 199 & $59.2 \%$ & 137 & $40.8 \%$ & 58 & $17.3 \%$ & 278 & $82.7 \%$ \\
\hline \multicolumn{13}{|c|}{ Panel B: Derivative contracts by year } \\
\hline & \multicolumn{4}{|c|}{ Foreign currency hedging } & \multicolumn{4}{|c|}{$\underline{\text { Interest rate hedging }}$} & \multicolumn{4}{|c|}{ Commodity price hedging } \\
\hline \multirow{3}{*}{2005} & FU & FO & OP & SW & $\mathrm{FU}$ & FO & OP & SW & $\mathrm{FU}$ & FO & OP & SW \\
\hline & 1 & 181 & 19 & 91 & 1 & 15 & 30 & 171 & 12 & 18 & 14 & 19 \\
\hline & $0.4 \%$ & $62.9 \%$ & $6.6 \%$ & $31.6 \%$ & $0.4 \%$ & $5.2 \%$ & $10.4 \%$ & $59.4 \%$ & $4.2 \%$ & $6.3 \%$ & $4.9 \%$ & $6.6 \%$ \\
\hline \multirow[t]{2}{*}{2006} & 3 & 188.0 & 23 & 90.0 & 1 & 12 & 32 & 175 & 14 & 22 & 15 & 19 \\
\hline & $1.0 \%$ & $63.5 \%$ & $7.8 \%$ & $30.4 \%$ & $0.3 \%$ & $4.1 \%$ & $10.8 \%$ & $59.1 \%$ & $4.7 \%$ & $7.4 \%$ & $5.1 \%$ & $6.4 \%$ \\
\hline \multirow[t]{2}{*}{2007} & 3 & 199 & 27 & 97 & 1 & 16 & 28 & 188 & 13 & 24 & 17 & 19 \\
\hline & $1.0 \%$ & $65.0 \%$ & $8.8 \%$ & $31.7 \%$ & $0.3 \%$ & $5.2 \%$ & $9.2 \%$ & $61.4 \%$ & $4.3 \%$ & $7.8 \%$ & $5.6 \%$ & $6.2 \%$ \\
\hline \multirow[t]{2}{*}{2008} & 2 & 211 & 28 & 98 & 1 & 15 & 26 & 195 & 15 & 32 & 17 & 24 \\
\hline & $0.6 \%$ & $67.9 \%$ & $9.0 \%$ & $31.5 \%$ & $0.3 \%$ & $4.8 \%$ & $8.4 \%$ & $62.8 \%$ & $4.8 \%$ & $10.3 \%$ & $5.4 \%$ & $7.7 \%$ \\
\hline \multirow[t]{2}{*}{2009} & 2 & 217 & 28 & 100 & 1 & 14 & 25 & 202 & 12 & 33 & 17 & 23 \\
\hline & $0.6 \%$ & $68.9 \%$ & $8.9 \%$ & $31.8 \%$ & $0.3 \%$ & $4.4 \%$ & $7.9 \%$ & $64.1 \%$ & $3.8 \%$ & $10.5 \%$ & $5.4 \%$ & $7.3 \%$ \\
\hline \multirow[t]{2}{*}{2010} & 2 & 220 & 27 & 104 & 1 & 12 & 25 & 206 & 13 & 27 & 15 & 24 \\
\hline & $0.6 \%$ & $68.3 \%$ & $8.4 \%$ & $32.3 \%$ & $0.3 \%$ & $3.7 \%$ & $7.8 \%$ & $64.0 \%$ & $4.0 \%$ & $8.4 \%$ & $4.7 \%$ & $7.5 \%$ \\
\hline \multirow[t]{2}{*}{2011} & 2 & 225 & 27 & 112 & 1 & 15 & 23 & 207 & 14 & 32 & 17 & 24 \\
\hline & $0.6 \%$ & $69.2 \%$ & $8.3 \%$ & $34.5 \%$ & $0.3 \%$ & $4.6 \%$ & $7.1 \%$ & $63.7 \%$ & $4.3 \%$ & $9.9 \%$ & $5.2 \%$ & $7.4 \%$ \\
\hline \multirow[t]{2}{*}{2012} & 1 & 226 & 22 & 110 & 1 & 16 & 22 & 201 & 13 & 34 & 17 & 23 \\
\hline & $0.3 \%$ & $68.7 \%$ & $6.7 \%$ & $33.4 \%$ & $0.3 \%$ & $4.9 \%$ & $6.7 \%$ & $61.1 \%$ & $4.0 \%$ & $10.3 \%$ & $5.2 \%$ & $7.0 \%$ \\
\hline \multirow[t]{2}{*}{2013} & 2 & 231 & 27 & 110 & 1 & 14 & 18 & 211 & 15 & 34 & 21 & 27 \\
\hline & $0.6 \%$ & $68.6 \%$ & $8.0 \%$ & $32.6 \%$ & $0.3 \%$ & $4.2 \%$ & $5.3 \%$ & $62.6 \%$ & $4.5 \%$ & $10.1 \%$ & $6.2 \%$ & $8.0 \%$ \\
\hline \multirow[t]{2}{*}{2014} & 2 & 230 & 26 & 110 & 1 & 14 & 17 & 210 & 13 & 32 & 22 & 31 \\
\hline & $0.6 \%$ & $66.5 \%$ & $7.5 \%$ & $31.8 \%$ & $0.3 \%$ & $4.1 \%$ & $4.9 \%$ & $60.7 \%$ & $3.7 \%$ & $9.3 \%$ & $6.4 \%$ & $9.0 \%$ \\
\hline \multirow[t]{2}{*}{2015} & 2 & 233 & 27 & 111 & 0 & 14 & 16 & 213 & 15 & 33 & 22 & 36 \\
\hline & $0.6 \%$ & $66.6 \%$ & $7.7 \%$ & $31.7 \%$ & $0.0 \%$ & $4.0 \%$ & $4.6 \%$ & $60.9 \%$ & $4.3 \%$ & $9.4 \%$ & $6.3 \%$ & $10.3 \%$ \\
\hline \multirow[t]{2}{*}{2016} & 3 & 232 & 28 & 110 & 0 & 13 & 15 & 207 & 11 & 33 & 19 & 35 \\
\hline & $0.9 \%$ & $66.5 \%$ & $8.0 \%$ & $31.5 \%$ & $0.0 \%$ & $3.7 \%$ & $4.3 \%$ & $59.3 \%$ & $3.2 \%$ & $9.5 \%$ & $5.4 \%$ & $10.0 \%$ \\
\hline 2017 & 3 & 232 & 28 & 110 & 0 & 13 & 14 & 198 & 12 & 29 & 20 & 34 \\
\hline & $0.9 \%$ & $66.5 \%$ & $8.0 \%$ & $31.5 \%$ & $0.0 \%$ & $3.9 \%$ & $4.2 \%$ & $58.9 \%$ & $3.6 \%$ & $8.6 \%$ & $6.0 \%$ & $10.1 \%$ \\
\hline
\end{tabular}

Notes: This table reports statistics on the popularity of hedging for each financial risk and derivative contract, for the period between 2005 and 2017. Panel A reports the number and the percentage of hedgers $(H>0)$ and nonhedgers $(H=0)$ for the financial risks. The percentages of hedgers and nonhedgers are computed based on a total sample of 378 firms and 4210 firm-years. Panel B shows the popularity of each derivatives contract: futures (FU), forwards (FO), options (OP) and swaps (SW) for hedging different types of risks: foreign currency (FX), interest rate (IR) and commodity price (CM). The numbers in panel B do not necessarily add up to the numbers in panel A because firms use multiple contracts to hedge the same risk. 
Table 2

Descriptive statistics for the hedging-related variables and other firm characteristics

\begin{tabular}{|c|c|c|c|c|c|c|c|c|c|}
\hline \multicolumn{5}{|l|}{ Panel A: Hedging related variables } & \multicolumn{5}{|l|}{ Panel B: Explanatory and instrumental variables } \\
\hline & Mean & Std. dev. & Min. & Max. & & Mean & Std. dev. & Min. & Max. \\
\hline Hedging decisions & 0.835 & 0.371 & 0.000 & 1.000 & & & & & \\
\hline Foreign exchange hedge dummy (FXH) & 0.716 & 0.451 & 0.000 & 1.000 & Revenue (£bn) & 4.328 & 18.017 & 0.000 & 294.787 \\
\hline FXFU dummy & 0.007 & 0.083 & 0.000 & 1.000 & Total Assets (£bn) & 5.475 & 19.273 & 0.008 & 333.151 \\
\hline FXFO dummy & 0.668 & 0.471 & 0.000 & 1.000 & Return on Assets (ROA) & 0.065 & 0.097 & -0.690 & 0.995 \\
\hline FXOP dummy & 0.080 & 0.271 & 0.000 & 1.000 & Net Income (£bn) & 0.293 & 1.644 & -21.916 & 59.254 \\
\hline FXSW dummy & 0.320 & 0.467 & 0.000 & 1.000 & Firm Market Value (£bn) & 4.844 & 14.759 & 0.003 & 207.965 \\
\hline Interest rate hedge dummy (IRH) & 0.618 & 0.486 & 0.000 & 1.000 & Tobin's Q (ln) & 0.634 & 0.469 & -1.680 & 4.390 \\
\hline IRFU dummy & 0.002 & 0.049 & 0.000 & 1.000 & Firm Size (ln Assets) & 2.990 & 0.746 & 0.891 & 5.520 \\
\hline IRFO dummy & 0.044 & 0.204 & 0.000 & 1.000 & Firm Age (ln Age) & 1.180 & 0.405 & 0.000 & 3.000 \\
\hline IROP dummy & 0.069 & 0.254 & 0.000 & 1.000 & Leverage & 0.219 & 0.177 & 0.000 & 0.990 \\
\hline IRSW dummy & 0.614 & 0.487 & 0.000 & 1.000 & Floating Rate Debt & 0.915 & 0.278 & 0.000 & 1.000 \\
\hline Commodity hedge dummy (CMH) & 0.163 & 0.370 & 0.000 & 1.000 & Fixed Rate Debt & 0.684 & 0.465 & 0.000 & 1.000 \\
\hline CMFU dummy & 0.041 & 0.198 & 0.000 & 1.000 & Dividends per share & 0.173 & 0.271 & 0.000 & 3.580 \\
\hline CMFO dummy & 0.091 & 0.288 & 0.000 & 1.000 & Dividends dummy & 0.852 & 0.355 & 0.000 & 1.000 \\
\hline CMOP dummy & 0.055 & 0.229 & 0.000 & 1.000 & Capex/assets & 0.044 & 0.045 & 0.000 & 0.583 \\
\hline \multirow[t]{2}{*}{ CMSW dummy } & 0.080 & 0.272 & 0.000 & 1.000 & $\mathrm{R} \& \mathrm{D} /$ assets & 0.012 & 0.041 & 0.000 & 0.731 \\
\hline & & & & & Geographical diversification & 0.838 & 0.368 & 0.000 & 1.000 \\
\hline Foreign currency only & 0.187 & 0.390 & 0.000 & 1.000 & Number of segments (ln) & 0.887 & 0.611 & 0.000 & 2.300 \\
\hline Interest rate only & 0.093 & 0.291 & 0.000 & 1.000 & Foreign Sales Ratio & 0.529 & 0.389 & 0.000 & 1.000 \\
\hline Commodity only & 0.010 & 0.099 & 0.000 & 1.000 & Foreign Expenditures & 0.873 & 0.333 & 0.000 & 1.000 \\
\hline Futures only & 0.001 & 0.031 & 0.000 & 1.000 & Commodity Purchases & 0.195 & 0.396 & 0.000 & 1.000 \\
\hline Forwards only & 0.141 & 0.348 & 0.000 & 1.000 & Commodity Oil \& Gas, Mining, Energy & 0.114 & 0.318 & 0.000 & 1.000 \\
\hline Options only & 0.001 & 0.038 & 0.000 & 1.000 & & & & & \\
\hline Swaps only & 0.127 & 0.333 & 0.000 & 1.000 & & & & & \\
\hline
\end{tabular}

Notes: This table shows summary statistics for 378 non-financial firms listed in London Stock Exchange (LSE) over the time period between 2005 and 2017 on firm characteristics and the usage of derivatives. The sample size for both panels is 4210 firm-years. All variables are defined in the Appendix. 
Table 3

Treatment effects regressions regarding the impact of hedging financial risks on firm performance and value

\begin{tabular}{|c|c|c|c|c|c|}
\hline Variables & Coef. & Std. Dev. & Wald $\chi^{2}$ & Log likelihood & LR test statistics, $\chi^{2}$ (p-value) \\
\hline \multicolumn{6}{|c|}{ Panel A: Impact of hedging financial risks on firm performance } \\
\hline Foreign exchange hedge & 0.004 & $(0.009)$ & $724.7^{* * *}$ & 1836 & 0.108 \\
\hline Interest rate hedge & $-0.026 * * *$ & $(0.007)$ & $684.8^{* * *}$ & 1856 & 0.869 \\
\hline Commodity price hedge & $-0.015^{* *}$ & $(0.007)$ & $737.6^{* * *}$ & 3093 & 0.435 \\
\hline \multicolumn{6}{|l|}{ Currency derivatives } \\
\hline Forwards & 0.009 & $(0.010)$ & $734.5^{* * *}$ & 1683 & 0.184 \\
\hline Options & -0.026 & $(0.022)$ & $737.9^{* * *}$ & 3026 & 0.431 \\
\hline Swaps & $0.123 * * *$ & $(0.005)$ & $1,243.0^{* * *}$ & 1673 & 0.000 \\
\hline \multicolumn{6}{|l|}{ Interest rate derivatives } \\
\hline Forwards & $0.103 * * *$ & $(0.012)$ & $803.4^{* * *}$ & 3540 & 0.000 \\
\hline Options & $-0.073 * * *$ & $(0.011)$ & $783.9^{* * *}$ & 3166 & 0.000 \\
\hline Swaps & $-0.070^{* * *}$ & $(0.008)$ & $754.7^{* * *}$ & 1664 & 0.000 \\
\hline \multicolumn{6}{|l|}{ Commodity derivatives } \\
\hline$\overline{\text { Futures }}$ & -0.015 & $(0.017)$ & $738.0^{* * *}$ & 3574 & 0.186 \\
\hline Forwards & -0.020 & $(0.017)$ & $733.0^{* * *}$ & 3086 & 0.395 \\
\hline Options & -0.023 & $(0.015)$ & $736.3^{* * *}$ & 3487 & 0.482 \\
\hline Swaps & $-0.024 *$ & $(0.014)$ & $733.8^{* * *}$ & 3159 & 0.150 \\
\hline \multicolumn{6}{|c|}{ Panel B: Impact of hedging financial risks on firm value } \\
\hline Foreign exchange hedge & $0.069 * *$ & $(0.031)$ & $2937^{* * *}$ & -3965 & 0.343 \\
\hline Interest rate hedge & $-0.178 * * *$ & $(0.039)$ & $2898^{* * *}$ & -4235 & 0.003 \\
\hline Commodity price hedge & 0.063 & $(0.057)$ & $2912^{* * *}$ & -3296 & 0.588 \\
\hline \multicolumn{6}{|l|}{ Currency derivatives } \\
\hline Forwards & $0.144 * * *$ & $(0.053)$ & $2966^{* * *}$ & -4231 & 0.157 \\
\hline Options & $0.338 * * *$ & $(0.044)$ & $3039^{* * *}$ & -2796 & 0.000 \\
\hline Swaps & $0.570 * * *$ & $(0.024)$ & $3634^{* * *}$ & -4208 & 0.000 \\
\hline \multicolumn{6}{|l|}{ Interest rate derivatives } \\
\hline Forwards & $0.572 * * *$ & $(0.042)$ & $3194^{* * *}$ & -2385 & 0.000 \\
\hline Options & $-0.422 * * *$ & $(0.043)$ & $3070^{* * *}$ & -2701 & 0.000 \\
\hline Swaps & $-0.177 * * *$ & $(0.039)$ & $2896^{* * *}$ & -4249 & 0.002 \\
\hline \multicolumn{6}{|l|}{ Commodity derivatives } \\
\hline Futures & $0.210 * * *$ & $(0.076)$ & $2945^{* * *}$ & -2158 & 0.070 \\
\hline Forwards & -0.103 & $(0.072)$ & $2912^{* * * *}$ & -2794 & 0.044 \\
\hline Options & $0.161 * *$ & $(0.065)$ & $2930^{* * * *}$ & -2289 & 0.053 \\
\hline Swaps & -0.015 & $(0.080)$ & $2918^{* * *}$ & -2560 & 0.856 \\
\hline
\end{tabular}

Notes: This table presents treatment effects estimates for the outcome model regarding the impact of derivatives use for hedging financial risks (FX, IR and CM) and contracts (futures, forwards, options and swaps) on performance based on (ROA) as a proxy in Panel A and on firm value based on Tobin's Q (ln) as a proxy in Panel B. We do not report treatment equation for each model in these regressions. In the treatment equation, we use instrumental and control variables to predict the fitted value of the treated variable. Likelihood ratio (LR) test reports diagnostic statistics for the null hypothesis that the correlation between the error terms of the treatment and outcome models is zero; i.e., examining whether each model is fitted, and estimated coefficients are not biased. The sample size is 4210 firm-years. The time and industry fixed effects and a constant term are included in all models. For brevity, we do not report the results for the control variables that are explained in section 3.2.3; they are available upon request. All variables are defined in the Appendix. Robust standard errors are reported in the parentheses alongside each coefficient estimate. ***, **, and * denote significance at the $1 \%, 5 \%$, and $10 \%$ level, respectively. 
Table 4

Matched sample tests: propensity score matching

\begin{tabular}{|c|c|c|c|c|}
\hline & Users & Non-users & & Robus \\
\hline & Sample & Sample & Difference & S.E. \\
\hline \multicolumn{5}{|c|}{ Panel A. Hedging Decisions } \\
\hline \multicolumn{5}{|c|}{ Foreign currency hedge (FX) } \\
\hline ROA & 0.064 & 0.067 & -0.003 & 0.005 \\
\hline $\ln Q$ & 0.653 & 0.610 & $0.043 * * *$ & 0.006 \\
\hline \multicolumn{5}{|c|}{ Interest rate hedge (IR) } \\
\hline ROA & 0.048 & 0.070 & $-0.022 * * *$ & 0.005 \\
\hline $\ln Q$ & 0.603 & 0.642 & $-0.039 * *$ & 0.016 \\
\hline \multicolumn{5}{|c|}{ Commodity price hedge $(\mathrm{CM})$} \\
\hline ROA & 0.046 & 0.066 & $-0.020 * * *$ & 0.005 \\
\hline $\ln \mathrm{Q}$ & 0.710 & 0.634 & $0.076 * * *$ & 0.029 \\
\hline \multicolumn{5}{|c|}{ Panel B. Derivatives Use for Hedging FX Risks } \\
\hline \multicolumn{5}{|c|}{ Forwards (FO) } \\
\hline ROA & 0.063 & 0.073 & -0.010 & 0.006 \\
\hline $\ln Q$ & 0.682 & 0.591 & $0.091 * * *$ & 0.008 \\
\hline \multicolumn{5}{|c|}{ Options (OP) } \\
\hline ROA & 0.051 & 0.066 & -0.015 & 0.012 \\
\hline $\ln Q$ & 0.672 & 0.639 & $0.033 * * *$ & 0.012 \\
\hline \multicolumn{5}{|c|}{ Swaps (SW) } \\
\hline ROA & 0.054 & 0.065 & -0.011 & 0.010 \\
\hline $\ln Q$ & 0.650 & 0.615 & $0.035^{* *}$ & 0.017 \\
\hline \multicolumn{5}{|c|}{ Panel C. Derivatives Use for Hedging IR Risks } \\
\hline \multicolumn{5}{|c|}{ Forwards (FO) } \\
\hline ROA & 0.119 & 0.065 & 0.054 & 0.043 \\
\hline $\ln Q$ & 0.691 & 0.630 & 0.061 & 0.085 \\
\hline \multicolumn{5}{|c|}{ Options (OP) } \\
\hline ROA & 0.039 & 0.065 & $-0.026^{* * *}$ & 0.003 \\
\hline $\ln Q$ & 0.481 & 0.633 & $-0.152 * * *$ & 0.035 \\
\hline \multicolumn{5}{|c|}{ Swaps (SW) } \\
\hline ROA & 0.051 & 0.077 & $-0.026^{* * *}$ & 0.006 \\
\hline $\operatorname{lnQ}$ & 0.655 & 0.599 & $-0.056^{* * *}$ & 0.014 \\
\hline \multicolumn{5}{|c|}{ Panel D. Derivatives Use for Hedging CM Risks } \\
\hline \multicolumn{5}{|c|}{ Futures (FU) } \\
\hline ROA & 0.007 & 0.065 & $-0.058 * * *$ & 0.007 \\
\hline $\ln Q$ & 0.666 & 0.634 & $0.032^{* * * *}$ & 0.009 \\
\hline \multicolumn{5}{|c|}{ Forwards (FO) } \\
\hline ROA & 0.029 & 0.066 & $-0.037 * * *$ & 0.006 \\
\hline $\ln Q$ & 0.489 & 0.632 & $-0.143^{* * *}$ & 0.031 \\
\hline \multicolumn{5}{|c|}{ Options (OP) } \\
\hline ROA & 0.026 & 0.067 & $-0.041 * *$ & 0.017 \\
\hline $\ln Q$ & 0.757 & 0.631 & 0.126 & 0.157 \\
\hline \multicolumn{5}{|c|}{ Swaps (SW) } \\
\hline ROA & 0.052 & 0.066 & $-0.014 * * *$ & 0.004 \\
\hline $\operatorname{lnQ}$ & 0.473 & 0.634 & $-0.161 * * *$ & 0.016 \\
\hline
\end{tabular}

Notes: This table presents the differential effects of hedging on the outcome (i.e., value and performance) variables by comparing the non-users with the users of derivative instruments during the period from 2005 to 2017. Last two columns report difference between the coefficients pertaining to the two groups and the corresponding standard errors, respectively. Panel A shows the results for the overall hedging decisions. Panel B (C) (D) shows the results for the FX (IR) (CM) risk using different derivative contracts. All estimations use robust Abadie and Imbens standard errors. Regressions in the pre-treatment variables modelling hedging are based on Probit model with determinants of derivatives use that were explained in the previous tables. After creating the matched sample, the number of matched cases in panel A for FX, IR and CM hedging are 1,195, 2,602 and 3,523, respectively; in panel B, they are 1,399 (forwards), 3,873 (options) and 2,861 (swaps); in panel C, they are 4,027 (forwards), 3,919 (options) and 1,626 (swaps); and in panel D, they are 4,038 (futures), 3,827 (forwards), 3,977 (options) and 3,872 (swaps). We do not report estimations for all the explanatory variables to conserve space. We also control for industry effects by using industry dummies based on SIC codes and control for time effects by using year dummies. All variables are defined in the Appendix. ***, **, and $*$ denote significance at the $1 \%, 5 \%$, and $10 \%$ level, respectively. 
Table 5

Firm performance and value with derivatives use across time periods: PSM estimates

\begin{tabular}{|c|c|c|c|c|c|c|c|c|}
\hline & \multicolumn{2}{|c|}{ Pre-crisis (1) } & \multicolumn{2}{|c|}{ Post-crisis (2) } & \multicolumn{2}{|c|}{ During crisis (3) } & \multicolumn{2}{|c|}{ Non-crisis (4) } \\
\hline & Coef. & S.E. & Coef. & S.E & Coef. & S.E & Coef. & S.E \\
\hline \multicolumn{9}{|c|}{ Panel A. Overall hedging decisions } \\
\hline \multicolumn{9}{|c|}{ Foreign currency hedge $(\mathrm{FX})$} \\
\hline ROA & 0.005 & 0.006 & $-0.031 * * *$ & 0.010 & -0.004 & 0.003 & -0.027 & 0.018 \\
\hline $\ln Q$ & $0.105 * * *$ & 0.035 & $0.012 *$ & 0.007 & $0.031 * * *$ & 0.011 & $0.071 * * *$ & 0.019 \\
\hline \multicolumn{9}{|c|}{ Interest rate hedge (IR) } \\
\hline ROA & 0.008 & 0.009 & $-0.028 * * *$ & 0.006 & $-0.016^{* *}$ & 0.007 & $-0.021 * * *$ & 0.005 \\
\hline $\ln Q$ & $-0.134 * * *$ & 0.032 & $-0.056^{*}$ & 0.022 & $-0.093 * * *$ & 0.027 & $-0.082 * * *$ & 0.020 \\
\hline \multicolumn{9}{|c|}{ Commodity price hedge $(\mathrm{CM})$} \\
\hline ROA & $-0.056^{* * *}$ & 0.010 & $-0.032 * * *$ & 0.006 & $-0.026^{* * *}$ & 0.005 & $-0.029 * * *$ & 0.004 \\
\hline $\ln Q$ & $-0.143^{* * *}$ & 0.029 & -0.001 & 0.023 & $-0.061 * *$ & 0.029 & $0.063 * * *$ & 0.017 \\
\hline \multicolumn{9}{|c|}{ Panel B. Derivatives use for hedging FX risks } \\
\hline \multicolumn{9}{|c|}{ Forwards $(\mathrm{FO})$} \\
\hline ROA & $-0.015^{* *}$ & 0.006 & -0.004 & 0.004 & -0.006 & 0.008 & $-0.005^{* *}$ & 0.002 \\
\hline $\ln Q$ & $0.050^{* *}$ & 0.028 & $0.059 * * *$ & 0.021 & 0.040 & 0.032 & $0.051 * * *$ & 0.004 \\
\hline \multicolumn{9}{|c|}{ Options (OP) } \\
\hline ROA & -0.004 & 0.006 & $-0.011 * *$ & 0.005 & 0.003 & 0.004 & $-0.008 * *$ & 0.003 \\
\hline $\ln Q$ & $-0.025 *$ & 0.014 & $0.038^{*}$ & 0.021 & -0.051 & 0.054 & $0.024 * * *$ & 0.006 \\
\hline \multicolumn{9}{|c|}{$\underline{\text { Swaps (SW) }}$} \\
\hline ROA & -0.002 & 0.003 & -0.006 & 0.007 & $0.017 *$ & 0.010 & -0.004 & 0.003 \\
\hline $\ln \mathrm{Q}$ & 0.049 & 0.042 & $0.083^{* *}$ & 0.041 & -0.035 & 0.035 & $0.062 * * *$ & 0.019 \\
\hline \multicolumn{9}{|c|}{ Panel C. Derivatives use for hedging IR risks } \\
\hline \multicolumn{9}{|c|}{$\underline{\text { Forwards }(\mathrm{FO})}$} \\
\hline ROA & 0.021 & 0.019 & 0.014 & 0.020 & $-0.032 *$ & 0.016 & $0.012^{* *}$ & 0.005 \\
\hline $\ln Q$ & -0.100 & 0.208 & 0.053 & 0.140 & $-0.103 * * *$ & 0.039 & 0.095 & 0.203 \\
\hline \multicolumn{9}{|c|}{ Options (OP) } \\
\hline ROA & 0.007 & 0.030 & $-0.031 * * *$ & 0.005 & 0.003 & 0.027 & $-0.016 * * *$ & 0.005 \\
\hline $\ln Q$ & $-0.147 *$ & 0.084 & -0.062 & 0.041 & -0.075 & 0.086 & $-0.166^{* * *}$ & 0.024 \\
\hline \multicolumn{9}{|c|}{$\underline{\text { Swaps }(\mathrm{SW})}$} \\
\hline ROA & -0.006 & 0.009 & $-0.025 * * *$ & 0.004 & $-0.015^{*}$ & 0.006 & $-0.028 * * *$ & 0.008 \\
\hline $\ln Q$ & $-0.137 * * *$ & 0.042 & $-0.065 * *$ & 0.028 & $-0.110^{* * *}$ & 0.038 & $-0.060^{* * *}$ & 0.017 \\
\hline
\end{tabular}


Table 5 (continued): Panel D. Derivatives use for hedging CM risks

\begin{tabular}{|c|c|c|c|c|c|c|c|c|}
\hline \multicolumn{9}{|c|}{ Futures (FU) } \\
\hline ROA & $0.089^{*}$ & 0.051 & $-0.016^{* * *}$ & 0.004 & 0.004 & 0.024 & $-0.020 * * *$ & 0.004 \\
\hline $\ln Q$ & -0.022 & 0.019 & $0.117 * *$ & 0.047 & -0.182 & 0.136 & -0.002 & 0.043 \\
\hline \multicolumn{9}{|c|}{ Forwards (FO) } \\
\hline ROA & $-0.012 * * *$ & 0.004 & $-0.035 * * *$ & 0.006 & $-0.034 * * *$ & 0.003 & $-0.035 * * *$ & 0.007 \\
\hline $\ln Q$ & -0.090 & 0.065 & $-0.235^{* * * *}$ & 0.060 & $-0.250 * * *$ & 0.023 & $-0.237 * * *$ & 0.060 \\
\hline \multicolumn{9}{|c|}{ Options (OP) } \\
\hline ROA & -0.039 & 0.028 & -0.037 & 0.032 & $-0.029^{* * *}$ & 0.011 & $-0.062 * * *$ & 0.018 \\
\hline $\ln Q$ & $-0.139 * *$ & 0.067 & $0.215^{* *}$ & 0.088 & 0.021 & 0.033 & 0.012 & 0.077 \\
\hline \multicolumn{9}{|c|}{ Swaps (SW) } \\
\hline ROA & -0.030 & 0.022 & $-0.017 * * *$ & 0.003 & -0.004 & 0.010 & $-0.016^{* * *}$ & 0.004 \\
\hline $\operatorname{lnQ}$ & $0.192 *$ & 0.108 & $-0.162 * * *$ & 0.027 & 0.025 & 0.116 & $-0.098 * * *$ & 0.010 \\
\hline
\end{tabular}


Table 6

Firm performance and value with derivatives use across time periods: DDM estimates

\begin{tabular}{|c|c|c|c|c|}
\hline & \multicolumn{2}{|c|}{$\begin{array}{l}\text { Post-crisis vs. } \\
\text { Pre-crisis (1) }\end{array}$} & \multicolumn{2}{|c|}{$\begin{array}{l}\text { During crisis vs. } \\
\text { Non-crisis (2) }\end{array}$} \\
\hline & Coef. & S.E & Coef. & S.E \\
\hline \multicolumn{5}{|c|}{ Panel A. Hedging decisions } \\
\hline \multicolumn{5}{|c|}{ Foreign currency hedge (FX) } \\
\hline ROA & 0.010 & 0.008 & $0.028 *$ & 0.017 \\
\hline $\ln Q$ & $0.129 * *$ & 0.054 & 0.031 & 0.059 \\
\hline \multicolumn{5}{|c|}{ Interest rate hedge (IR) } \\
\hline ROA & $-0.022 *$ & 0.012 & $0.030 *$ & 0.018 \\
\hline $\ln Q$ & -0.021 & 0.050 & -0.026 & 0.044 \\
\hline \multicolumn{5}{|c|}{ Commodity price hedge (CM) } \\
\hline ROA & -0.013 & 0.022 & $0.023 *$ & 0.011 \\
\hline $\ln Q$ & $-0.177 * *$ & 0.076 & 0.057 & 0.045 \\
\hline \multicolumn{5}{|c|}{ Panel B. Derivatives use for hedging FX risks } \\
\hline \multicolumn{5}{|c|}{ Forwards (FO) } \\
\hline ROA & 0.004 & 0.011 & 0.003 & 0.011 \\
\hline $\ln Q$ & $0.113^{* * *} *$ & 0.040 & 0.025 & 0.046 \\
\hline \multicolumn{5}{|c|}{ Options (OP) } \\
\hline ROA & -0.008 & 0.010 & 0.010 & 0.010 \\
\hline $\ln Q$ & 0.002 & 0.052 & -0.046 & 0.058 \\
\hline \multicolumn{5}{|c|}{ Swaps (SW) } \\
\hline ROA & -0.011 & 0.007 & 0.004 & 0.008 \\
\hline $\ln Q$ & 0.014 & 0.031 & -0.025 & 0.041 \\
\hline \multicolumn{5}{|c|}{ Panel C. Derivatives use for hedging IR risks } \\
\hline \multicolumn{5}{|c|}{ Forwards (FO) } \\
\hline ROA & -0.013 & 0.011 & -0.003 & 0.018 \\
\hline $\ln Q$ & -0.018 & 0.058 & $-0.202^{* * *}$ & 0.073 \\
\hline \multicolumn{5}{|c|}{ Options (OP) } \\
\hline ROA & $-0.019 *$ & 0.010 & -0.005 & 0.013 \\
\hline $\ln Q$ & -0.038 & 0.047 & 0.006 & 0.056 \\
\hline \multicolumn{5}{|c|}{$\underline{\text { Swaps (SW) }}$} \\
\hline ROA & -0.005 & 0.010 & 0.007 & 0.012 \\
\hline \multirow[t]{2}{*}{$\ln Q$} & 0.008 & 0.049 & $-0.124^{* *}$ & 0.053 \\
\hline & & Deriv & risks & \\
\hline \multicolumn{5}{|c|}{ Futures (FU) } \\
\hline ROA & 0.027 & 0.019 & 0.004 & 0.013 \\
\hline $\ln Q$ & $0.089^{*}$ & 0.052 & $-0.127 * *$ & 0.059 \\
\hline \multicolumn{5}{|c|}{ Forwards (FO) } \\
\hline ROA & -0.024 & 0.017 & $0.020 *$ & 0.011 \\
\hline $\ln Q$ & -0.038 & 0.055 & 0.041 & 0.055 \\
\hline \multicolumn{5}{|c|}{ Options (OP) } \\
\hline ROA & -0.012 & 0.019 & 0.012 & 0.017 \\
\hline $\ln Q$ & 0.032 & 0.066 & -0.057 & 0.084 \\
\hline \multicolumn{5}{|c|}{ Swaps (SW) } \\
\hline ROA & -0.003 & 0.011 & 0.011 & 0.012 \\
\hline $\ln Q$ & -0.029 & 0.049 & 0.023 & 0.057 \\
\hline
\end{tabular}

Notes: This table presents the differential effects of hedging on firm value and performance by comparing the non-users with the users of derivative instruments during different time periods using the DDM setting by comparing two sub-periods. The dependent variable is ROA for performance, and Tobin's Q for value. The first step of this method is based on a Probit model that estimates the propensity to hedge, using robust Abadie and Imbens standard errors with five nearest-neighbors (nneighbor) with replacement and pstolerance (1e-10) robustness options. In this step, the same factors (i.e., the firm-specific characteristics and industry fixed effects) of our previous analyses were utilized as the variables influencing hedging decisions. In the second step, the DiD estimations based on the nearest-neighbor PSM specification obtain the difference between outcomes regarding the two periods, using robust Epanechnikov Kernel standards errors with default bandwidth (0.06) to alleviate concerns about serial correlation. The 'with replacement' option produces more reliable matching than the 'without replacement' option as in the former one firm can be used more than once as a match. The DDM method performs the PSM technique that generates reweighted treatment and control group in both time periods, i.e., the baseline and follow-up periods. We have panels of reasonably balanced treatment and control groups in the matched samples within each sub-period. To conserve space, we do not report estimations for all the explanatory variables. The columns in each model report both the coefficient estimates for this semi-parametric method and the corresponding standard errors. Panels A, B, C and D show the results for the overall hedging decisions, FX hedging, IR hedging and CM hedging, respectively, using different derivative contracts. We control for industry effects by using industry dummies based on the SIC codes. All variables are defined in the Appendix. ***, $* *$, and $*$ denote significance at the $1 \%, 5 \%$, and $10 \%$ level, respectively. 
Table 7

Treatment effects regressions for hedging a specific risk only or using a specific contract only

\begin{tabular}{|c|c|c|c|c|c|c|c|c|c|c|c|c|c|c|}
\hline & \multicolumn{7}{|c|}{ Panel A: Performance (ROA) } & \multicolumn{7}{|c|}{ Panel B: Firm value (lnQ) } \\
\hline & (1) & (2) & (3) & (4) & (5) & (6) & (7) & (8) & $(9)$ & $(10)$ & $(11)$ & $(12)$ & (13) & (14) \\
\hline Foreign currency only & $\begin{array}{c}0.120 * * * \\
(0.006)\end{array}$ & & & & & & & $\begin{array}{c}0.264^{* * * *} \\
(0.056)\end{array}$ & & & & & & \\
\hline Interest rate only & & $\begin{array}{l}-0.025^{*} \\
(0.014)\end{array}$ & & & & & & & $\begin{array}{c}-0.306 * * * * \\
(0.038)\end{array}$ & & & & & \\
\hline Commodity price only & & & $\begin{array}{l}-0.022 \\
(0.028)\end{array}$ & & & & & & & $\begin{array}{c}0.103 \\
(0.232)\end{array}$ & & & & \\
\hline Futures only & & & & $\begin{array}{c}0.139 \\
(0.014)\end{array}$ & & & & & & & $\begin{array}{l}-0.095 \\
(0.356)\end{array}$ & & & \\
\hline Forwards only & & & & & $\begin{array}{c}0.101 * * * \\
(0.008)\end{array}$ & & & & & & & $\begin{array}{c}0.234 * * * \\
(0.054)\end{array}$ & & \\
\hline Options only & & & & & & $\begin{array}{c}0.095 \\
(0.068)\end{array}$ & & & & & & & $\begin{array}{l}-0.452 * \\
(0.237)\end{array}$ & \\
\hline Swaps only & & & & & & & $\begin{array}{c}-0.025^{*} \\
(0.012)\end{array}$ & & & & & & & $\begin{array}{c}-0.316^{* * * *} \\
(0.036)\end{array}$ \\
\hline $\begin{array}{l}\text { Wald } \chi^{2} \\
\text { Log likelihood }\end{array}$ & $\begin{array}{c}1122 * * * \\
2242\end{array}$ & $\begin{array}{c}725 * * * \\
3096\end{array}$ & $\begin{array}{c}736 * * * \\
4009\end{array}$ & $\begin{array}{c}733 * * * * \\
4167\end{array}$ & $\begin{array}{l}889 * * * \\
2546\end{array}$ & $\begin{array}{c}738^{* * * *} \\
4153\end{array}$ & $\begin{array}{c}716^{* * * *} \\
2776\end{array}$ & $\begin{array}{c}2961 * * * * \\
3653\end{array}$ & $\begin{array}{c}2972 * * * \\
2770\end{array}$ & $\begin{array}{c}2920 * * * \\
1915\end{array}$ & $\begin{array}{c}2927 * * * * \\
1709\end{array}$ & $\begin{array}{c}2949 * * * * \\
3332\end{array}$ & $\begin{array}{c}2924 * * * * \\
1722\end{array}$ & $\begin{array}{c}2985 * * * \\
3079\end{array}$ \\
\hline $\begin{array}{l}\text { LR test statistics } \\
\chi^{2} \text { (p-value) }\end{array}$ & 0.000 & 0.451 & 0.472 & 0.757 & 0.000 & 0.501 & 0.3721 & 0.001 & 0.000 & 0.568 & 0.356 & 0.001 & 0.280 & 0.000 \\
\hline
\end{tabular}




\section{Figures}

As a general note for all figures, $R M$ (No RM) denotes the presence (absence) of risk management activities and Spec stands for speculative trading. Figures 1 to 5 represent high true managerial ability $(\gamma=10)$ and the horizontal axes represent increasing overconfidence (a manager's overestimation of his ability) in the range $\gamma=10$ to $\gamma=19$. Figures 6 and 11 represent low true managerial ability $(\gamma=0)$ and the horizontal axes represent increasing overconfidence in the range $\gamma=0$ to $\gamma=9$.

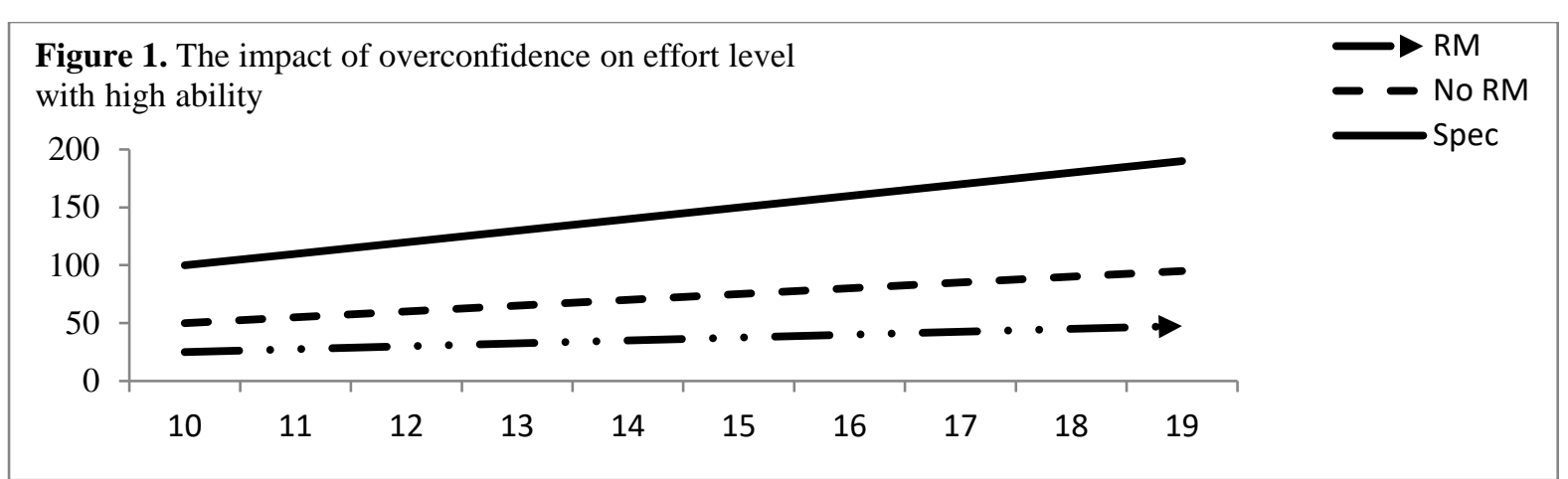

Notes: High (true) ability managerial optimal effort level: a) this is increasing in overconfidence for each strategy, and b) for a given level respectively, as the manager is motivated to chase the upside.

Figure 2. The impact of overconfidence on firm value with

high ability

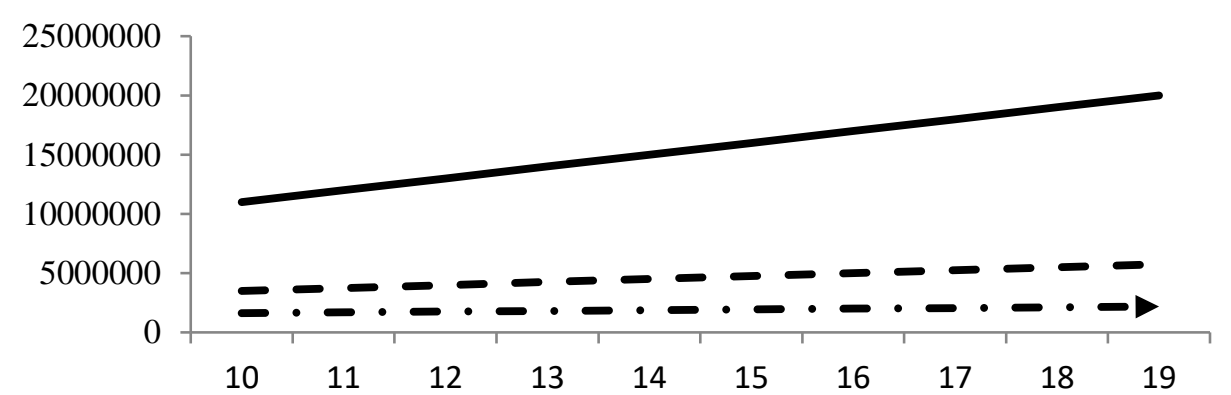

Notes: This is related to managers with high ability and the effect of overconfidence on the true value of the firm V. As is the case with, and due to, the manager's optimal effort level (in figure 1), a) this is increasing in overconfidence for each strategy, and b) for a given level of overconfidence, firm value is highest/medium/lowest for the speculative strategy/no risk-management/risk management strategies, respectively. 


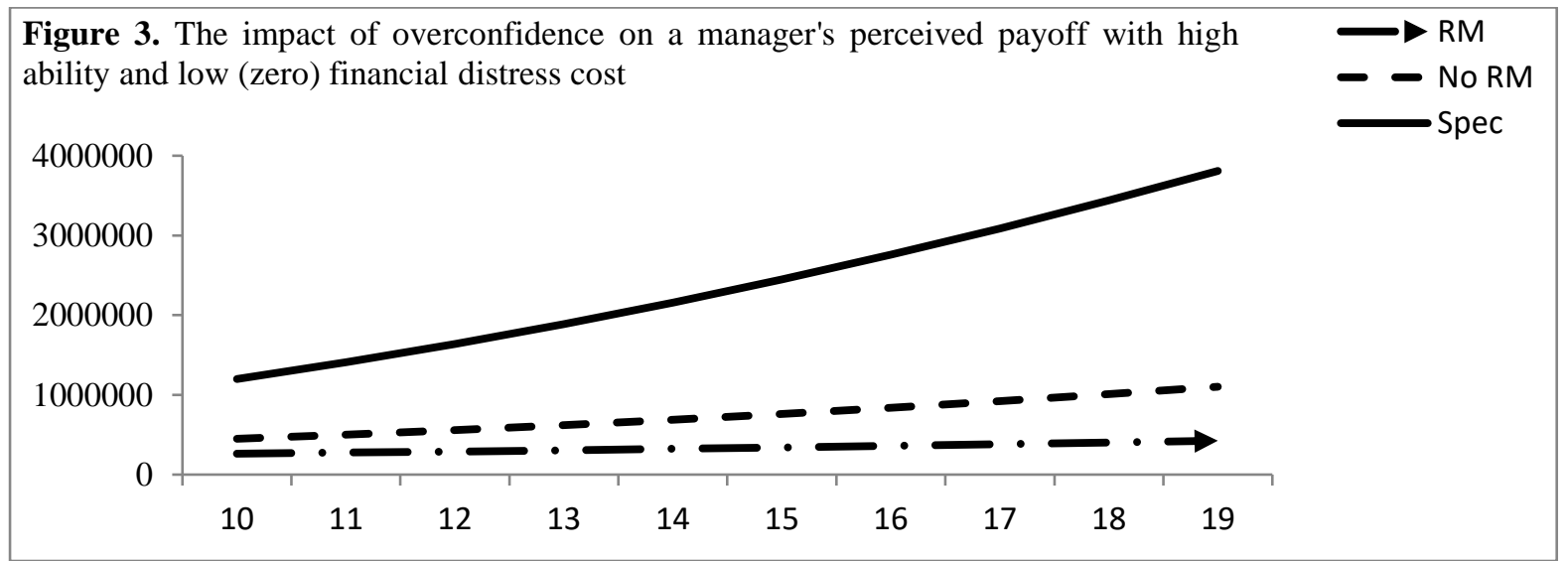

Notes: This is related to high ability of managers with zero/low personal financial distress costs $\left(\mathrm{F}_{\mathrm{M}}=0\right)$. The manager's perceived payoff is a) increasing in overconfidence for each strategy, and b) for a given level of overconfidence, his payoff is highest/medium/lowest for the speculative strategy/no risk-management/risk management strategies, respectively. Note that the manager faces zero financial distress costs in the downside. Thus, he unambiguously chooses the speculative strategy for any level of overconfidence. Since he has high true ability, this maximises true value for any level of overconfidence (see figure 2).

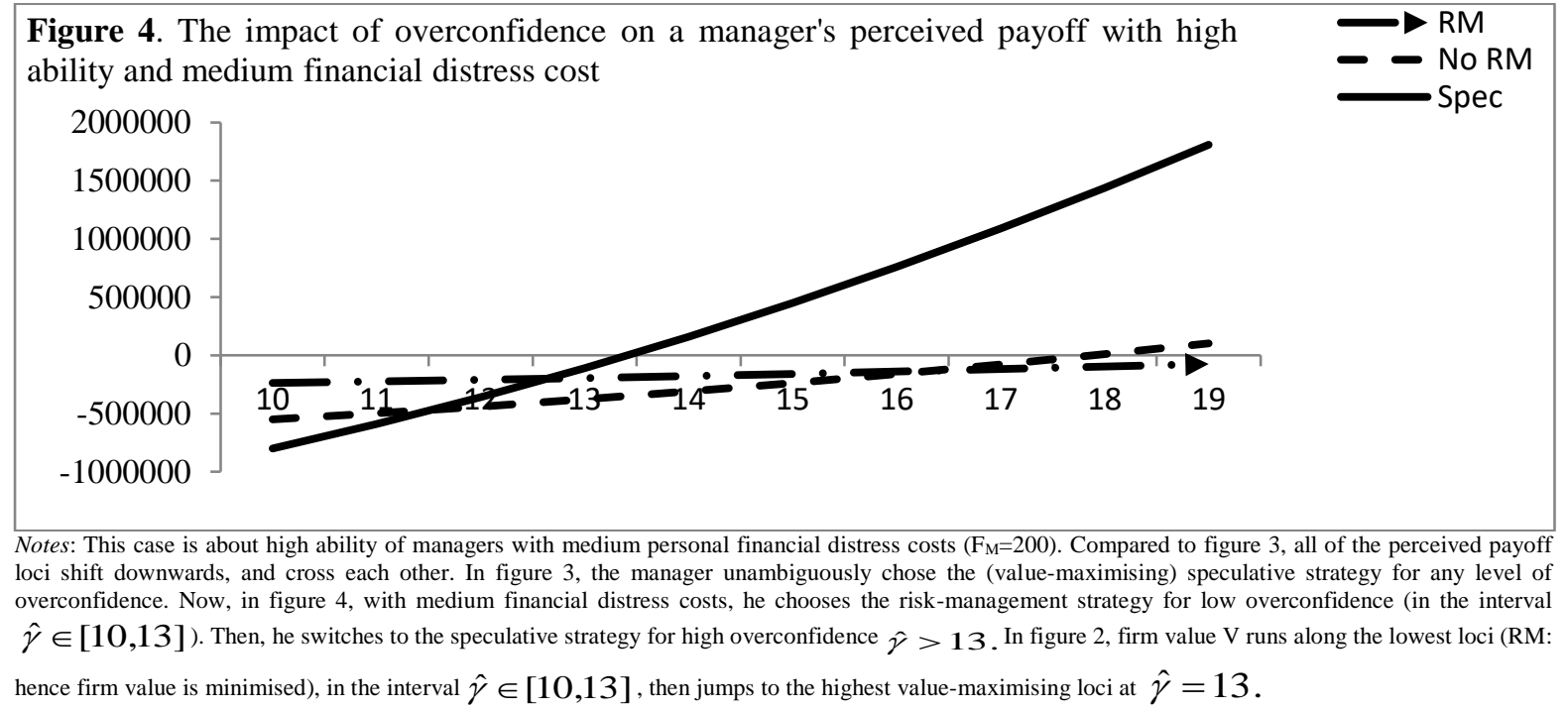




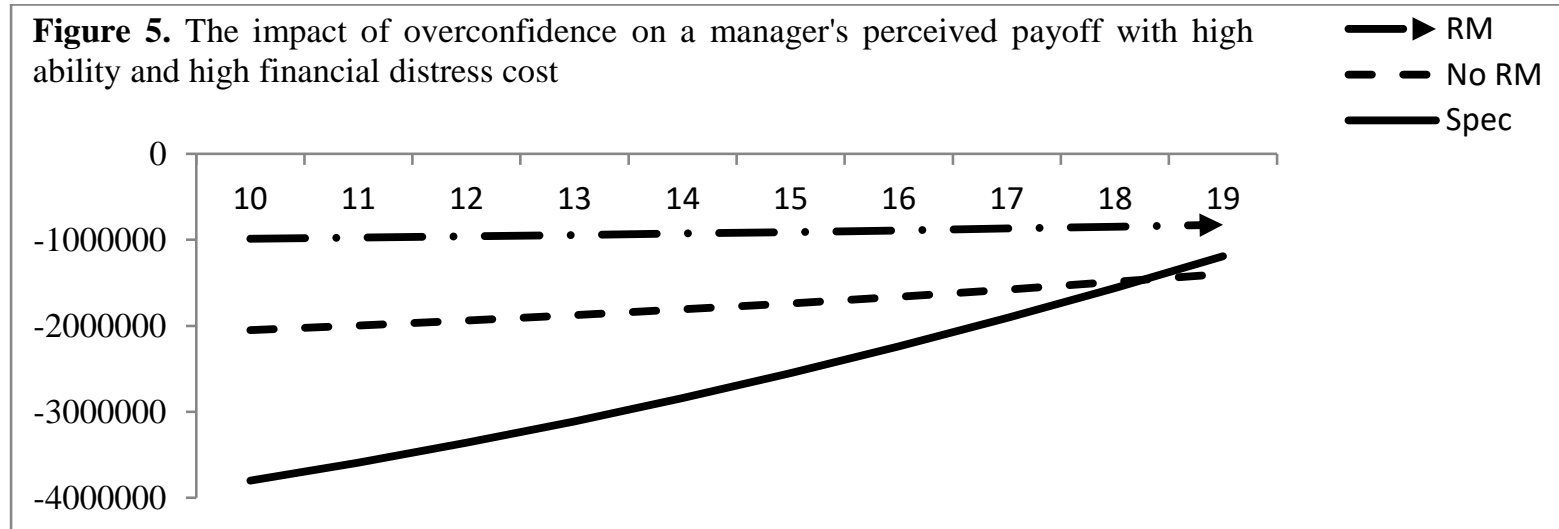

Notes: This case is about high ability of managers with high personal financial distress costs $\left(\mathrm{F}_{\mathrm{M}}=500\right)$. Compared with figure 4 , high financial distress costs cause the perceived payoff loci for non-risk-management and speculative strategies to shift downwards below the risk management strategy for any level of overconfidence. Now, personal financial distress costs dominate overconfidence, and the manager chooses risk management for any level of overconfidence. Notice that in figure 2, this minimises firm value (the lowest loci).

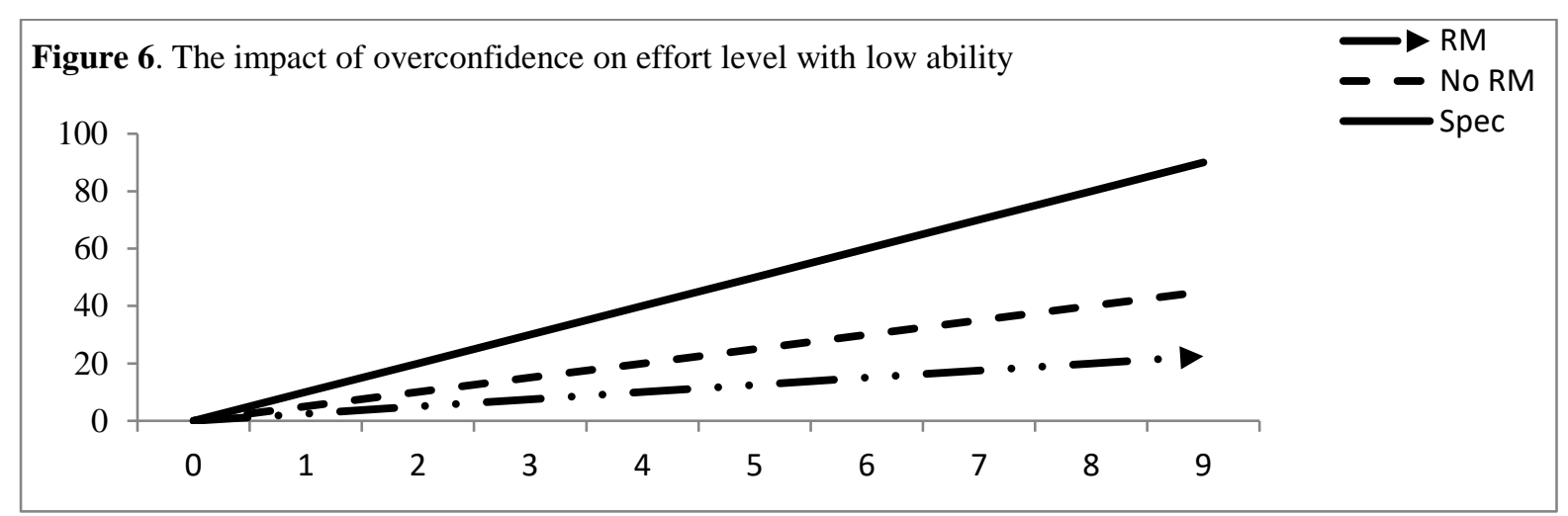

Notes: This case is about low (true) ability of managers and optimal effort level. As in figure 1, a) this is increasing in overconfidence for each strategy, and b) for a given level of overconfidence, effort is highest/medium/lowest for the speculative strategy/no riskmanagement/risk management strategies, respectively, as the manager is motivated to chase the upside. Although the shape of the diagram is the same as in figure 1, note the vertical axes in each diagram: due to a lower range of ability-overconfidence, the optimal effort levels are lower in figure 6 than those in figure 1 


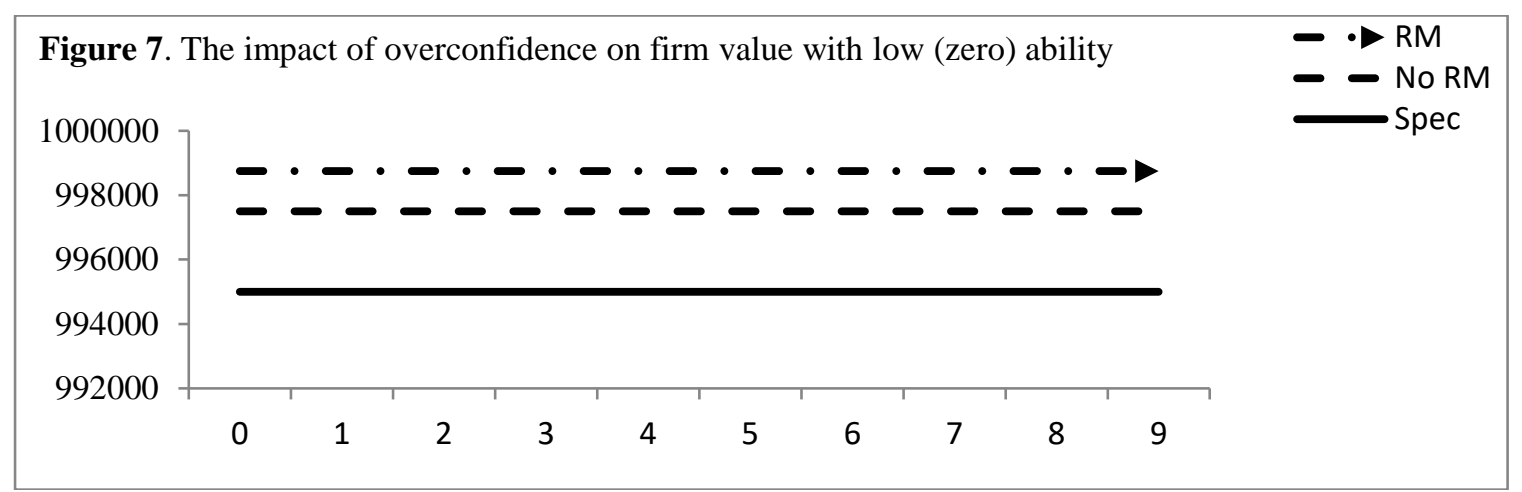

Notes: This case is about low (zero) ability of managers and examines the effect of overconfidence on the true value of the firm V. Since the manager has zero true ability, his effort level has no effect on the true value of the firm (hence, the horizontal loci). Thus, in contrast to figure 2 (where firm value was maximised under speculation, due to high managerial ability), firm value is now maximised under risk management for any level of overconfidence (due to low managerial ability).

Figure 8. The impact of overconfidence on a manager's perceived payoff with low ability and low (zero) financial distress cost
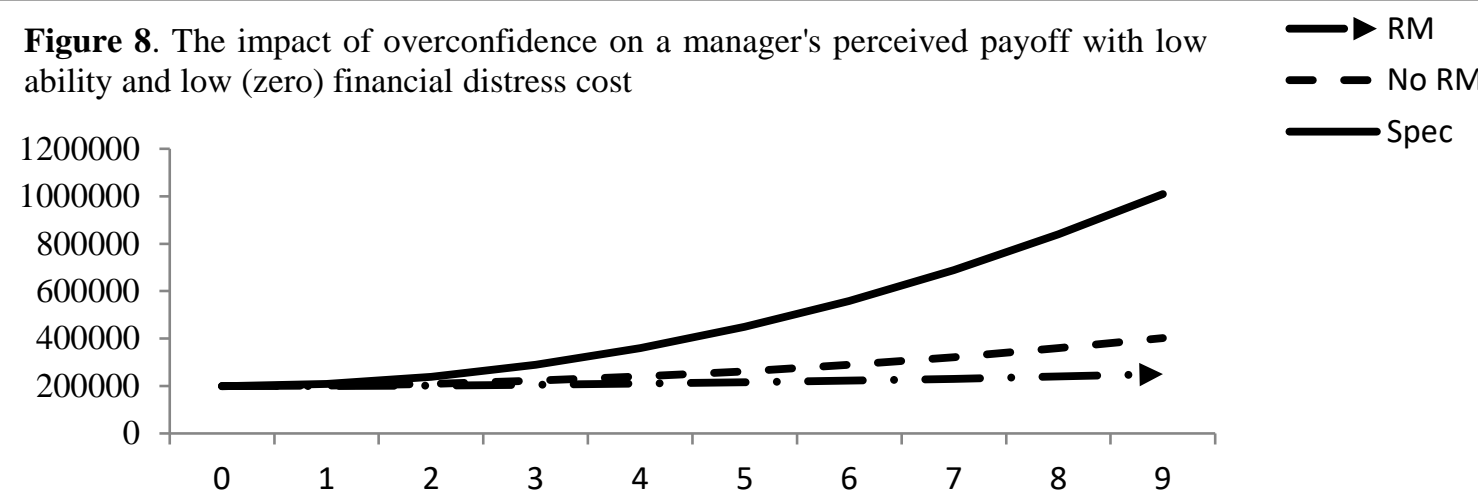

Notes: This case is about low ability of managers with zero personal financial distress costs $\left(\mathrm{F}_{\mathrm{M}}=0\right)$. The manager's perceived payoff is a) increasing in overconfidence for each strategy, and b) for a given level of overconfidence, his payoff is highest/medium/lowest for the speculative strategy/no risk-management/risk management strategies, respectively. Note that the manager faces zero financial distress costs in the downside. Thus, he unambiguously chooses the speculative strategy for any level of overconfidence. Since he has low true ability, this minimises true value for any level of overconfidence (see figure 7 and note the contrast with the high ability case). 


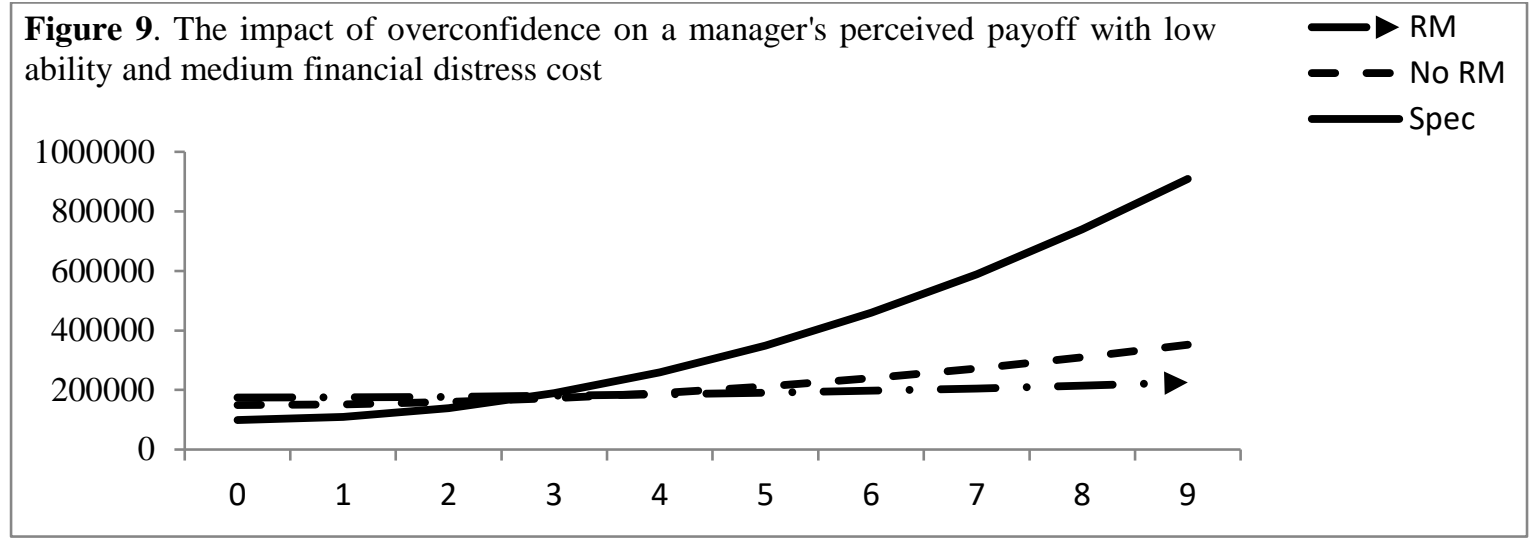

Notes: This case is about low ability of managers with medium personal financial distress costs for the managers. $\left(\mathrm{F}_{\mathrm{M}}=10\right)$. Compared to figure 8, all of the perceived payoff loci shift downwards, and cross each other. In figure 8, the manager unambiguously chose the (value-minimising) speculative strategy for any level of overconfidence. Now, in figure 9 , he chooses the risk-management strategy for low overconfidence (in the interval $\hat{\gamma} \in[0,3]$ ). Then, he switches to the speculative strategy for high overconfidence $\hat{\gamma}>3$. In figure 7, firm value $V$ runs along the highest loci (RM: hence firm value is maximised). When $\hat{\gamma}>3$, the overconfident manager switches to the speculative strategy, and firm value jumps down to the lowest locus in figure 7 . Note the contrast with the high ability case, where the speculative strategy maximised firm value. Now, in the low ability case, it minimises it.

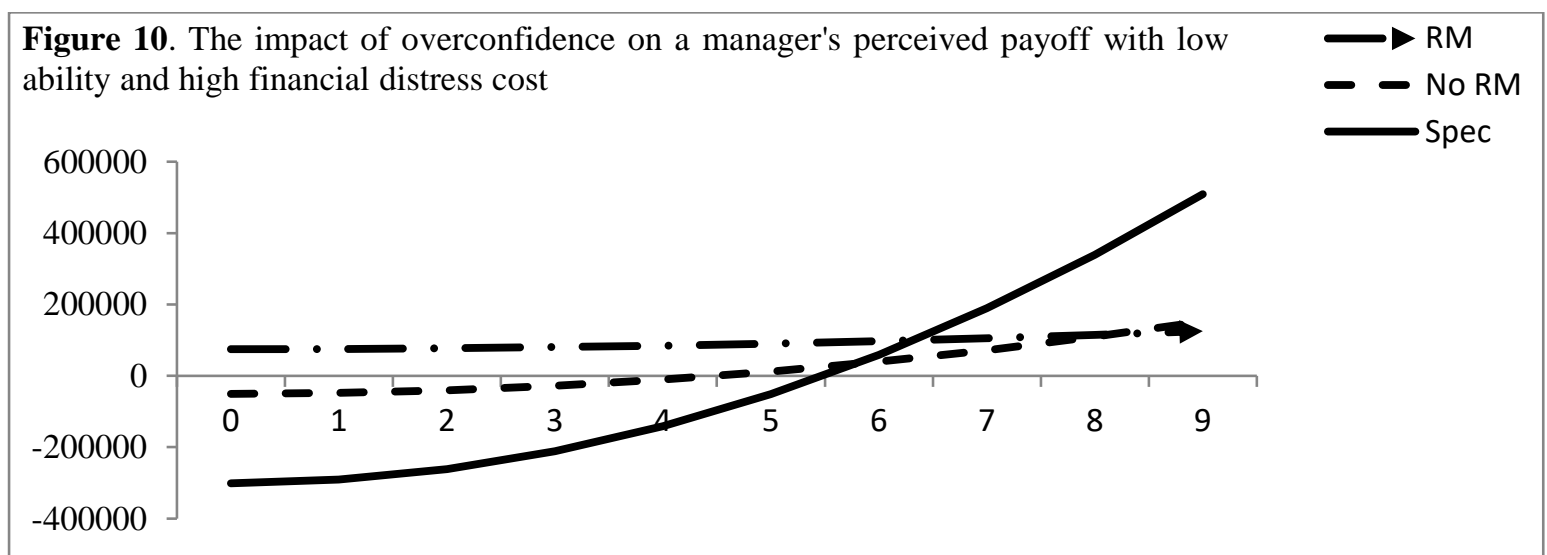

Notes: This case is about low ability of managers with high personal financial distress costs $\left(\mathrm{F}_{\mathrm{M}}=50\right)$. As personal financial distress costs increase, the loci shift further downwards. Now, the overconfidence range in which the manager chooses the risk-management strategy increases from $\hat{\gamma} \in[0,3]$ to $\hat{\gamma} \in[0,6]$. Then, he switches to the speculative strategy for high overconfidence $\hat{\gamma}>6$. In figure 7 , firm value $\mathrm{V}$ runs along the lowest loci (RM: hence firm value is minimised), in the interval $\hat{\gamma} \in[0,6]$, then jumps downwards to the lowest value-maximising loci at $\hat{\gamma}=6$. 
Figure 11. The impact of overconfidence on a manager's perceived payoff with low

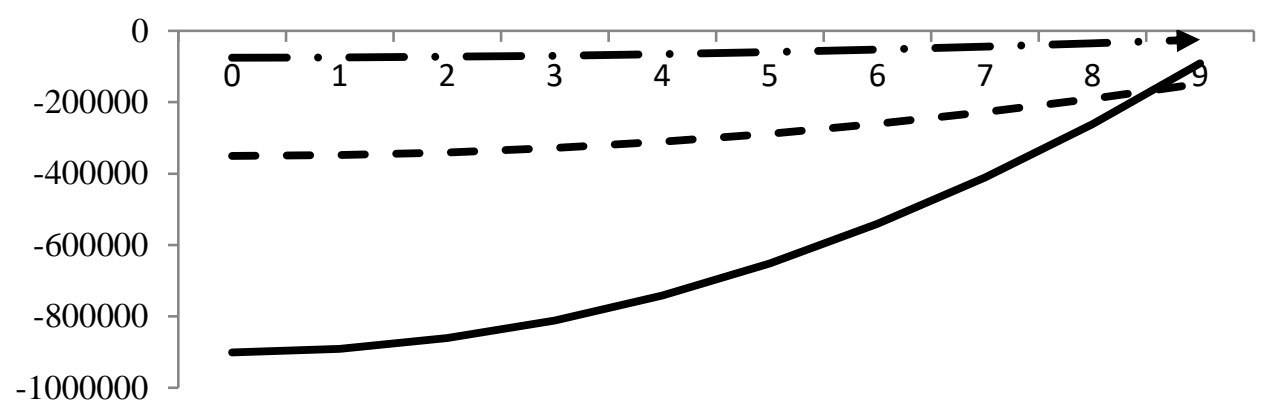

Spec

Notes: This case is about low ability of managers with very high personal financial distress costs $\left(\mathrm{F}_{\mathrm{M}}=110\right)$. In the case of very high personal financial distress costs, the speculative and no risk-management loci have shifted down so far, suggesting that the riskmanagement locus dominates for all levels of overconfidence. Thus, the manager chooses the value-maximising risk-management strategy for any level of overconfidence. 


\section{Notes}

${ }^{1}$ We note that our theoretical model analyses hedging/speculation generally without consideration of specific derivative instruments, or types of risk. However, this remains informative for our empirical analysis, as the model shows that hedging/speculation can lead to value-destruction or value-creation, depending on a combination of economic and behaviour al factors. We then show, empirically, that hedging with different derivatives can create or reduce value: the model helps us to understand these effects generally. For future research it would be desirable to develop the model further to consider the effect of individual derivatives. See the 'conclusion' section for further discussion of this point.

${ }^{2}$ For example, Tesco plc uses index-linked swaps to hedge cash flows on index-linked debt, interest rate swaps to hedge interest cash flows on debt and cross-currency swaps to hedge cash flows on fixed rate debt denominated in foreign currencies. The Group also uses forward contracts to hedge the future purchase of diesel for own use. Cash flow hedging ineffectiveness resulted in a loss of $£ 57 \mathrm{~m}$ during the year (2016: a loss of $£ 50 \mathrm{~m})$. The gain or loss on the hedging instrument and hedged item is recognised in the Group income statement within finance income or costs. Rolls-Royce Holdings plc has entered into a series of financial instruments to hedge its currency, interest rate and commodity exposures. The Group uses commodity swaps to manage its exposure to movements in the price of commodities (jet fuel and base metals). To hedge the currency risk associated with a borrowing denominated in US dollars, the Group has currency derivatives designated as part of fair value hedges. RollsRoyce uses interest rate swaps and forward rate agreements to manage its exposure to movements in interest rates. The company reported mixed results of net fair value gains $(£ 2,648 \mathrm{~m})$ and losses $(£ 4,420 \mathrm{~m})$ in 2017 and 2016 , respectively, when using various instruments to hedge its exposure to financial risks (FX, IR and $\mathrm{CM}$ ).

3 This method employs two simultaneous equations using full information maximum likelihood estimation: i) probit treatment equation that predicts the probability of hedging financial risks and also derivatives instruments use determined by a set of variables; ii) outcome equations for performance and value (ROA and $\operatorname{lnQ})$ as a function of the fitted values of the treated variables for hedging risks overall (FX, IR and CM) and also derivative contracts (futures, forwards, options and swaps) utilized for each specific risk, among other factors. The variables for the treatment equations are mentioned in notes to the tables for firm performance and value regression models, which are in line with the extant literature.

${ }^{4}$ For the TE setting, the null hypothesis in the likelihood ratio test statistics (LR) is that the correlation between the error terms of the outcome model and treatment model is zero (i.e., Ho: $\rho=0$ ). In Table 4, the results show that there is significant self-section bias in about half of the models and in Table 5 we strongly reject this hypothesis in most cases, suggesting that self-selection bias is indeed a significant issue to be addressed.

${ }^{5}$ In the Heckman model that addresses the sample selection bias the researcher can differentiate between the factors affecting the outcome (in our case value or performance) and treatment (i.e., hedging decision). This may cause some concerns including the multicollinearity among the determining factors. However, the advantage of the PSM method is that it does not require such a differentiation.

${ }^{6}$ In this paper, estimating the effects of hedging FX and IR on value and performance in PSM method is based on a probit treatment model with Stata $15^{\circledR}$ 's “teffects psmatch" command and the default option nneighbor (1) that specifies the number of matches per observation. However, in estimating the effects of hedging CM risk overall and its related derivatives, we increase the fixed number of matches to nneighbor $(5 ; 10 ; 20)$ in robustness checks when the PSM specification is violated by covariate imbalances. Using a fixed number for the nearest-neighbor approach is robust to more efficient matching estimators until the balance and overlap assumptions are settled down.

${ }^{7}$ We did not need to manually set any further scalar options like "caliper" with "nneighbor" to specify the maximum distance for which two observations are potential neighbors. We used "caliper" matching with "pstolerance" option only when examining the effect of FX on performance using options to satisfy the balance test. Moreover, we kept the default bandwidth in the estimator in the levels of significance given that using the bandwidth is a common choice in empirical applications (e.g., Busso et al., 2014). Such an adjustment with "nneighbor" is important for the scalar propensity score to be sufficient to remove or eliminate bias, especially in small observations in a finite sample (Rosenbaum and Rubin, 1983). Matching estimators require a good overlap 
that asserts that the propensity score is strictly between 0 and 1 for a vector of covariates (Busso et al., 2014). Therefore, we further used a scalar option "pstolerance", using the default value of $1 e-5$ or value of $1 e-10$, when the overlap assumption on the model was violated, which ensures that the estimated propensity score is greater than this value.

${ }^{8}$ See notes to Table 5 and 8 for the steps and procedures followed to conduct the DDM analysis in Stata $15^{\circledR}$. We use the recently developed "diff" Stata command that is based on the combination of Kernel PSM with DiD by which the control covariates can be used to match treated and control groups. 